\begin{tabular}{|c|l|}
\hline Title & $\begin{array}{l}\text { Surface velocities and ice front positions of eight major glaciers in the Southern Patagonian Ice Field, South A merica, } \\
\text { from 2002 to } 2011\end{array}$ \\
\hline Author(s) & Muto, minami; Furuya, Masato \\
\hline Citation & $\begin{array}{l}\text { Remote sensing of environment, 139,50-59 } \\
\text { https://doi.org/10.1016/.rse.2013.07.034 }\end{array}$ \\
\hline Issue Date & 2013.12 \\
\hline Doc URL & http://hdl.handle.net/2115/54777 \\
\hline Type & article (author version) \\
\hline File Information & furuya.pdf \\
\hline
\end{tabular}

Instructions for use 


\title{
Surface Velocities and Ice-Front Positions of Eight Major Glaciers in the Southern Patagonian Ice Field, South America, from 2002 to 2011
}

\author{
Minami Muto and Masato Furuya \\ Department of Natural History Sciences, Graduate School of Science, Hokkaido \\ University, N10W8, Kita-ku, Sapporo 060-0810, JAPAN.
}

\begin{abstract}
The Patagonian Ice Fields are known to have undergone rapid retreat of frontal positions and significant thinning of its glaciers over the past decades. However, surface velocities have been measured at only a few of these glaciers. Thus, it remains uncertain if and to what extent the glacier dynamics have changed over time and contributed to ice loss in these ice fields. In this study, we examine the temporal evolution of flow velocities and ice-front positions at eight major glaciers in the Southern Patagonian Ice Field (SPI; Hielo Patagónico Sur) by using Advanced Synthetic Aperture Radar (ASAR) images from the Environmental Satellite (Envisat) launched in 2002 by the European Space Agency and Advanced Land Observation Satellite/Phased Array-type L-band Synthetic Aperture Radar (ALOS/PALSAR) data recorded from 2002 to 2011. The examined eight glaciers include Glaciar Jorge Montt, Occidental, Pio XI (or Brüggen), O’Higgins, Viedma, Upsala, Perito Moreno, and Grey. Not all the glaciers revealed significant changes in frontal positions and flow velocities in the study period. We detected significant temporal velocity changes at Glaciar Upsala, Jorge Montt, Occidental, and Pio XI.
\end{abstract}


Among these four glaciers, Glaciars Upsala, Jorge Montt, and Occidental revealed significant acceleration and terminus retreat and were undergoing dynamic-thinning. The markedly different absolute velocities but equally large longitudinal near-terminus stretching at the three glaciers support a calving model based on crevasse-depth criteria, which predict a calving position where crevasse-depths are equal to ice thickness; crevasse-depths are controlled by the longitudinal stretching rate. Meanwhile, Glaciar Pio XI revealed complex spatial and temporal evolution in surface velocities without significant retreat, and its dynamics remain enigmatic.

Keywords: glacier velocity, Southern Patagonia, calving glacier, synthetic aperture radar

\section{Introduction}

The Southern Patagonian Ice Field (SPI; Hielo Patagónico Sur) contains 7 calving (Aniya et al., 1996). The ones on the western Chilean side mostly 
observation data recorded since 2002 indicate a total mass loss rate from both the Northern Patagonian Ice Field and the SPI to be ranging from $-23.0 \pm 9.0$ $\mathrm{Gt} \mathrm{a}^{-1}$ to $-26.0 \pm 6.0 \mathrm{Gt} \mathrm{a}^{-1}$ (Chen et al., 2007; Ivins et al., 2011; Jakob et al., 2012). GRACE-based mass-loss estimates in the beginning of the 21st century are larger than the corresponding volume loss rate derived in the late 20th century (Rignot et al., 2003). The recently reported surface height change rates, based on a time series of digital elevation models (DEMs), are also consistent with GRACE-based estimates, which indicates an even more rapid drawdown over the past decade (Willis et al., 2012).

While near-surface temperature increases associated with global warming presumably contribute to ice loss due to melting, the accelerated ice losses reported on Greenland and Antarctica have been linked to changes in glacier dynamics as well (Rignot and Kanagaratnam, 2006; van den Broeke et al., 2009; Pritchard et al., 2009). In particular, many polar glaciers that calve into the ocean have undergone significant acceleration, known as dynamic thinning, and have thus further contributed to ice loss. However, recent studies demonstrate spatial-temporal complexities of the outlet glacier velocities in Greenland (Moon et al., 2012; Bevan et al., 2012). In contrast to these large polar glaciers, no detailed glacier velocity maps are available for the Patagonian Ice Fields with the exception of those for certain accessible glaciers (Naruse et al., 1992, 1995; Stueffer et al., 2007; Sugiyama et al., 2011; Rivera et al., 2012a). Satellite-derived velocity maps are also limited to Glaciars Perito Moreno (Rott et al., 1998; Michel and Rignot, 1999; Ciappa et al., 2010) and Glaciar Upsala (Skvarca et al., 2003; Floricioiu et al., 2008, 2009; Sakakibara et al., 2013). Thus, it remains uncertain if and 
to what extent dynamic thinning has affected the Patagonian Ice Fields. In this study, we show the spatial and temporal changes in flow velocities at eight major glaciers in the SPI by applying an offset tracking technique to the intensity images of the Environmental Satellite/Advanced Synthetic Aperture Radar (Envisat/ASAR) and Advanced Land Observation Satellite/Phased Array-type L-band Synthetic Aperture Radar (ALOS/PALSAR) data recorded from 2002 to 2011. In addition, we used the cloud-free characteristics of SAR imagery for examining the terminus changes in order to determine whether the ice acceleration is associated with calving episodes. The examined eight glaciers include Glaciars Upsala, Jorge Montt, Occidental, Pio XI (or Brüggen), O’Higgins, Viedma, Perito Moreno, and Grey (Figure 1). We selected these glaciers not only because their sizes were sufficient to be imaged by the spatial resolution of presently available SAR data but also because they were more frequently imaged than others so that we could increase the temporal resolution, which allowed us to detect rapid changes in the ice dynamics.

As in the case of Greenland (Moon et al., 2012), we subsequently show that not all of the glaciers reveal ice acceleration and rapid terminus retreat. Submarine melting has been suggested as a principal triggering mechanism for the accelerated ice motion in Greenland, because the timing of the glacier's acceleration coincided with that of ocean water warming near Greenland (Holland et al., 2008; Rignot et al., 2010; Straneo et al., 2011). The rapid retreat and flow acceleration in the SPI, however, occur at both marine and fresh-water terminating glaciers, which suggests the presence of additional general processes independent of water salinity. While the physically 
based calving model remains elusive (Benn et al., 2007a), we interpret the observed data sets on the basis of the calving model based on crevasse-depth criteria (Benn et al., 2007a, b; Nick et al., 2010).

\section{Data and Analysis Method}

\subsection{Satellite data}

To generate glacier surface velocity maps, we processed the PALSAR images with a wavelength of $23.6 \mathrm{~cm}$ recorded from June 2007 to February 2011 from ALOS, which was launched in 2006 by the Japan Aerospace Exploration Agency (JAXA) (Table 1, Figure 1). To extend the analysis period further back to 2003, we also used the C-band (wavelength of $5.6 \mathrm{~cm}$ ) ASAR images from Envisat launched in 2002 by the European Space Agency (Table 1, Figure 1), which often contains de-correlation problems; the advantage of the L-band over C-band was shown before (Rignot, 2008; Strozzi et al., 2008). On the basis of our observations of insignificant temporal velocity changes at Glaciar Perito Moreno (supplementary material), the differences in penetration depths due to different wavelengths do not appear to affect the inferred velocities. This result is theoretically reasonable because the most significant changes in glacier-flow velocity profile are expected to occur near the glacier bed rather than near the surface (Cuffey and Patterson, 2010).

The off-nadir beam angle of PALSAR is $34.3^{\circ}$, which forms $\sim 39^{\circ}$ incident angle at the flat ground in the image center. There are two available imaging modes, fine beam single polarization (FBS, HH) and fine beam dual polarization (FBD; HH and HV). We used data from only $\mathrm{HH}$ polarization. The difference between FBS and FBD is the slant range (across track) reso- 
lution, which is $\sim 4.7 \mathrm{~m}$ for the FBS mode and $\sim 9.4 \mathrm{~m}$ for the FBD mode; the azimuth resolution is $3.1 \mathrm{~m}$ regardless of the mode. The FBD data are oversampled twice along the range axis. On the other hand, the ASAR data used in this study were obtained along a descending path with a local incidence beam angle of $\sim 23^{\circ}$; the ASAR data from an ascending path of the mode IS6 were used only for the analysis of Glaciar Perito Moreno (Table1, supplementary material). This smaller incidence angle lowers the sensitivity to the east-west component of displacement, although it can increase the sensitivity of the vertical component. The spatial resolution of ASAR in the slant range and azimuth direction is $7.8 \mathrm{~m}$ and $4.1 \mathrm{~m}$, respectively. We processed the PALSAR level 1.0 products and ASAR level 0 products to generate single look complex images.

\subsection{Pixel-offset tracking}

Although the other approaches are available, such as radar interferometry (Goldstein et al., 1993) and multiple aperture interferometry (Gourmelen et al., 2011), they are based on phase images that will encounter coherence loss and phase unwrapping problems to quantify larger displacements. In this study, pixel-offset tracking (intensity tracking or speckle tracking) algorithms, based on maximizing the cross-correlation of the radar image patches, were used to observe surface velocities (Michel et al., 1999; Strozzi et al., 2002; Yasuda and Furuya, 2013). We used the intensity tracking algorithm because it is most suitable for detecting rapidly-flowing glacier velocities with long data acquisition intervals (Strozzi et al., 2002, 2008). Although we experimented with a variety of patch sizes and sampling intervals, we eventually deemed a search patch of $\sim 500 \mathrm{~m}$ (range) $\times 600 \mathrm{~m}$ 
(azimuth) area with a sampling interval of $\sim 90 \mathrm{~m} \times 120 \mathrm{~m}$ as optimum parameters. We set a signal-to-noise ratio (SNR) threshold of 4.0; patches below this level were assigned to the missing data. Lower SNR data occur because of the large spatial separation length (Bperp) of the repeating orbits or temporal changes in the surface scattering characteristics; Bperp denotes the perpendicular component of the baseline projected onto the radar line of sight (LOS). Unfortunately, the Bperp for the PALSAR data pairs in summer was relatively long; however, the operational orbit determination accuracy is now approaching sub-meter level with standard errors of tens of centimeters or less (Scharroo and Visser, 1998; Andersen et al., 1998; Katagiri and Yamamoto, 2008). Moreover, because higher precipitation levels and temperatures occur in summer, we can consider that snowfall and surface melting lower the cross-correlation between the temporally separated image patches, which prevents derivation of velocity data, particularly in the accumulation zones. We did not mask the non-glacier areas in offset-tracking, because it was important to verify that non-glacier areas could indeed be estimated to be non-deforming, and that there were no artifacts due to topography. The no-displacement signals outside the glaciated areas shown below validated the surface velocity data detected along the glacier itself. Over the glaciated areas, however, we occasionally encountered spurious signals that indicated, for instance, extraordinary fast velocities or physically unrealistic discontinuities in the velocity distributions. We considered that these spurious data were caused by erroneous matching of objects that actually differed; thus, we visually eliminated such noise.

Because the satellite does not repeat exactly the same paths, the effect 
of fore-shortening also differs in each path, which results in an artifact offset over rugged terrain (Michel et al., 1999; Sansosti et al., 2006; Kobayashi et al., 2009). We reduced this artifact by applying an elevation-dependent co-registration by employing NASA's Shuttle Radar Topography Mission (SRTM-4) DEM data with a 3-arcsec resolution, in which the gaps in the original SRTM data were filled (Jarvis et al., 2008). Although the SRTM data may include inherent errors and are nearly a decade old, we used them because there are free of gaps and apparent noise. Because no topographycorrelated offsets were apparent, we considered the artifact offset to be adequately corrected; it is unlikely that the errors in the SRTM DEM influenced our velocity data.

The pixel-offset tracking technique provides range and azimuth offsets, both of which are linear combinations of the three-dimensional (3D) displacements. The range offset, $U_{r a}$, is a projection of the $3 \mathrm{D}$ surface displacements onto the slant radar LOS direction, while the azimuth offset, $U_{a z}$, is a projection of the 3D surface displacements along the satellite-track direction. Using the satellite's heading angle $H$ measured clockwise from the north and the microwave's incidence angle to the ground $I$, each offset can be represented as follows:

$$
\left(\begin{array}{c}
U_{r a} \\
U_{a z}
\end{array}\right)=\left(\begin{array}{lll}
\cos H \sin I & -\sin H \sin I & -\cos I \\
\sin H & \cos H & 0
\end{array}\right)\left(\begin{array}{c}
U_{e} \\
U_{n} \\
U_{z}
\end{array}\right)
$$

where $U_{e}, U_{n}$, and $U_{z}$ are defined as eastward, northward, and upward positive displacements, respectively. The imaging angles and expressions of $U_{r a}$ and $U_{a z}$ for each satellite's observation mode are indicated in Table 2. 
Because the two displacement maps do not allow us to resolve the 3D displacements, we derived the surface velocity data by using the parallel flow assumption (Joughin et al., 1996). Although either the range or azimuth offset data allow us to derive the surface velocity with the parallel flow assumption, we used both data sets to solve the over-determined problem by the least-squares method. The local topographic gradient vector was estimated from the SRTM-4 data. Because only the local flow orientation and slope angles are necessary in the argument of trigonometric functions for parallel flow approximation, the ice-thickness changes that may have occurred between the SRTM and PALSAR/ASAR data acquisition would be insignificant as potential error sources in the computation of a unit vector.

Although the effects of atmospheric propagation and inaccurate satellite orbit generate significant errors in the InSAR phase data, these errors are insignificant in the offset tracking data. This is because the errors in the offset tracking data are due to those in the image registration, and are larger than those due to atmospheric propagation and satellite orbit (Strozzi et al., 2002). The uncertainties of the offset measurements have been estimated to be $\sim 0.3$ $0.4 \mathrm{~m}$ at the non-deforming rugged terrain in the ALOS/PALSAR data with a 46-day interval (Kobayashi et al., 2009). If the ice is flowing at a constant rate over the data acquisition interval, the error in the velocity estimates can be inferred as $0.005-0.01 \mathrm{~m} /$ day, and will be inversely proportional to the data acquisition interval (Strozzi et al., 2002). However, errors in pixeloffset tracking can also originate from other sources. The most significant error source is the temporal de-correlation between image patches due to changes in objects' scattering properties. Thus, all the the data pairs shown 
in this study have the shortest possible 46- and 35-day temporal separation, which denote the PALSAR and ASAR recurrent periods, respectively. The ASAR data more often indicated larger errors, probably because the short wavelength data tend to undergo the de-correlation problem. The magnitude of errors also varies seasonally from less than $5 \mathrm{~m} / \mathrm{a}$ up to $30 \mathrm{~m} / \mathrm{a}$, depending on the season of the SAR data acquisition (Yasuda and Furuya, 2013).

For point sites such as those at the Glaciar Upsala and the site $\mathrm{C}$ at the Glaciar Jorge Montt, we averaged the velocities at the nearby $500 \mathrm{~m}^{2}$ area and considered the derived standard deviation as the measurement error, which ranges from less than $0.1 \mathrm{~m} /$ day to $\sim 0.5 \mathrm{~m} /$ day. For transverse velocity profile, we selected five velocity profiles that are closely-located within 100 $\mathrm{m}$, and computed the average and standard deviation along the transverse direction. The velocities and error bars for the transverse profiles shown below were derived by further averaging the data along the transverse direction; the velocity profiles and errors along the transverse direction are shown in the supplementary material.

\subsection{Ice-front position changes}

Cloud-free SAR intensity images permit the tracking of ice-front positions over time if clear image contrasts are present between the ice and water surfaces. By using the original single look complex images, the intensity images were derived by multi-looking in range and azimuth directions. The spatial resolution was $40 \mathrm{~m} \times 40 \mathrm{~m}$. We visually identified the ice-front positions at each SAR intensity image; we did not perform mechanized automatic detection. The front position change shown below is referenced to the first SAR image in 2002 or 2003, and represents the average change derived by dividing 
the total area of each polygon by a fixed width of a reference profile in the upstream direction (Moon and Joughin, 2008). Errors in digitized frontal positions arose mainly from our misidentification of the frontal positions, which could be attributed to image resolution and the lower image contrast between the ice and water surfaces. Images with unclear contrasts between the ice and water surfaces were not used in this study. Bevan et al. (2012) evaluated the accuracies of $\pm 49 \mathrm{~m}$ for ERS1/2 and ASAR SAR images. We consider that the accuracies of our identified frontal positions are comparable to or better than the Bevan et al's estimate, because the resolution is close to those of ERS1/2 and ASAR in PALSAR's FBD mode and better in PALSAR's FBS mode.

\section{Results}

Regarding temporal evolution of surface velocities at the eight large glaciers examined in this study from 2003 to 2011, Glaciars Upsala, Jorge Montt, Occidental, and Pio XI revealed significant acceleration of greater than 30 \%. Although temporal fluctuations possibly due to seasonalities were recognized, no large velocity changes were evident at Glaciars Grey, Perito Moreno, Viedma, and O'Higgins. With the exception of Pio XI, these accelerated glaciers also revealed significant retreating in the frontal positions. In this section, we present the observation results of the Glaciars Upsala, Jorge Montt, Occidental, and Pio XI; the results of the remaining glaciers are shown in the supplementary material. 


\subsection{Glaciar Upsala}

Glaciar Upsala, the third largest glacier in the SPI, contains three termini, of which the westernmost terminus is the largest and calves into Brazo Upsala of Lago Argentino (Skvarca et al., 2003). The water depth is 400$500 \mathrm{~m}$ (Naruse and Skvarca, 2000). A rapid retreat of the frontal position since 1978 has been reported (Aniya and Skvarca, 1992; Skvarca et al., 1995; Naruse et al., 1997; Naruse and Skvarca, 2000; Skvarca et al., 2002). The thinning rate near the glacier front was reported to be $11 \mathrm{~m} / \mathrm{a}$ between 1990

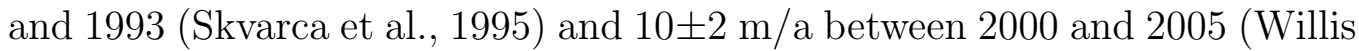
et al., 2012), but accelerated to $24.8 \pm 2.4 \mathrm{~m} / \mathrm{a}$ between 2005 and 2011 (Willis et al., 2012). Annual velocities near the terminus based on satellite imagery were first derived by Skvarca et al (2003), who applied a cross-correlation method to Landsat 7 Enhanced Thematic Mapper Plus (ETM+) images acquired between 2000 and 2001; this approach is similar to the currently used intensity tracking approach. Near the fastest-flowing western terminus, Skvarca et al (2003) derived average velocities of approximately $1600 \mathrm{~m} / \mathrm{a}$, equivalent to $4.4 \mathrm{~m} /$ day, which were in good agreement with the field measurement obtained in 1995 (Skvarca et al., 1995). Sakakibara et al (2013) extended the analysis period to 2011. On the basis of TerraSAR-X data acquired between December 2007 and January 2008, Floricioiu et al (2008) reported a maximum velocity of $5.6 \mathrm{~m} /$ day, which is significantly faster than the earlier observations in 1995 and 2001; Floricioiu et al (2009) extended the study period. However, the time at which the glacier initiated acceleration and the evolution of the frontal positions remain unknown.

Surface velocities near the terminus position could not be derived in this 
study because of the low SNR in the offset tracking near the ice front. We consider that the faster ice motion near the terminus caused significant temporal changes in the surface features and hence their scattering characteristics; the 46/35-day acquisition intervals in PALSAR/ASAR are too long for tracking the surface features of such a rapidly flowing region with sufficient correlation. However, the slower velocity data in the upstream could be derived; thus, we examined the temporal changes in velocities at two sites closer to the terminus (A and B in Figure 2a), in which the velocity data were acquired as frequently as possible. We averaged the velocities at 36 pixels (over $500 \mathrm{~m}^{2}$ ) for each site and assigned their standard deviations as the error bar in Figure 2b. One site was in the main stream of Glaciar Upsala, and the other was in Glaciar Bertachi, one of the western tributaries closest to the frontal position. Figure $2 \mathrm{~b}$ summarizes the temporal evolution of both surface velocities at the two sites and frontal positions derived in this study. Figure 3 shows the terminus locations visually identified over time. Although we could not generate useful velocity data between 2006 and 2010 because of a satellite orbit problem, we observed a nearly $180 \%$ velocity increase between 2005 and 2010 even at a point $7 \mathrm{~km}$ from the terminus in the main stream. From 2003 to 2005, the near-terminus velocities were $2 \mathrm{~m} /$ day, which are in agreement with Skvarca et al's observations in 2001 (Skvarca et al 2003). Even in Glaciar Bertachi, it is evident that the 2010 surface velocities are nearly 200 $\%$ those of the 2003-2005 data. In 2010-2011, therefore, the near-terminus region is apparently flowing faster than previously recorded speeds. The frontal position retreated nearly $3.5 \mathrm{~km}$ from 2002 to 2011 and approached the lower end of Glaciar Bertachi. The speed up on Bertacchi between July 
2010 and January 2011 may be associated with the recent retreat. Although the point A seems stable in Figure 2b, it is likely that the similar speed-up at point A occurred but was not detected by the available data. In view of the TerraSAR-X intensity image in Floricioiu et al (2008), the frontal position in January 2008 was close to that recorded in 2005. While the front gradually retreated from 2002 to 2005 with possible seasonal fluctuations (Figure 3), the retreating appears to have accelerated in August 2008.

\subsection{Glaciar Jorge Montt}

Glaciar Jorge Montt is located at the northern end of the SPI and calves into an unnamed fjord that opened as a result of its glacier retreat to a maximum of $19.5 \mathrm{~km}$ from 1898 to 2011 (Rivera et al., 2012b). The maximum thinning rate was estimated to be $17.9 \mathrm{~m} / \mathrm{a}$ between 1975 and 2000 (Rignot et al., 2003) and 21.5 $\pm 0.8 \mathrm{~m} / \mathrm{a}$ between 2000 and 2012 (Willis et al., 2012). In addition, the rate of glacier terminus retreat was estimated to be $200 \mathrm{~m} / \mathrm{a}$ between 2001 and 2011 (Willis et al., 2012).

So far, few surface velocity measurements of Glaciar Jorge Montt have been reported. Rivera et al (2012a) derived an average velocity of $13 \pm 4$ m/day for the near-terminus region between 2010 and 2011 by using both ground-based cameras and a feature tracking based on ASTER images. Comparing Rignot et al's unpublished velocity data derived from the 2004 C-band Radarsat-1 images, Rivera et al (2012a) suggested an acceleration between 2004 and 2010. However, the surface velocity data in the other years and up-glacier parts remain uncertain.

Figure 4a shows an example of a velocity map derived from data acquired between January and February 2008. Although we could not derive 
the velocity data near the terminus region as was the case for Glaciar Upsala, the derived velocity maps complement the observations of Rivera et al (2012a), because our velocity maps cover the middle to upstream regions of the glaciers. Figure 4b summarizes the temporal evolutions of both frontal location changes and the mean velocities at one flow velocity profile (A-B in Figure $4 \mathrm{a}$ ) and the other upstream site (C in Figure 4a). While the mean value of the $A-B$ profile is smaller than the mean at the $C$, this is due to the averaging procedure, and the flow velocity at the center of $\mathrm{A}-\mathrm{B}$ profile is higher than at $\mathrm{C}$; the velocities and errors along the transverse profile are shown in the supplementary. The measured velocity profile is located $5.5 \mathrm{~km}$ upstream from that measured by Rivera et al (2012a). Figure 5 indicates the frontal locations identified at each epoch. The relationship between the retreating rate and flow velocities from 2003 to 2007 remains uncertain because not all of the image pairs allowed us to derive the flow velocity data. However, both the retreating rate and flow velocities are not constant over time. Although the frontal position continued to retreat since 2003, it became stagnant from 2007 to 2008 when the flow velocities significantly decreased. From 2008 onward, the retreating rate apparently accelerated, indicating $\sim 470 \mathrm{~m} / \mathrm{a}$, and the flow velocities in 2011 increased by $130 \%$, compared to those recorded in 2003. While the flow acceleration reported by Rivera et al (2012a) was derived by comparing the data acquired in 2004 and 2010, Figure 4b suggests that the acceleration was initiated in 2008.

\subsection{Glaciar Occidental}

Glaciar Occidental is located on the western side of the SPI and flows into a proglacial lake. On the basis of the analysis of Landsat TM and Advanced 
Visible and Near Infrared Radiometer-2 (AVNIR-2) on ALOS images, the terminus retreat between 1986 and 2006 was estimated to be $1.1 \mathrm{~km}$, and the terminus shape was found to be disintegrated (JAXA, 2010). Regarding surface elevation change rate, Glaciar Occidental is also thinning at a rate of 2-5 m/a (Willis et al., 2012). To our knowledge, however, no flow velocity data have been published so far.

We selected two transverse profiles at downstream and upstream positions ( $\mathrm{A}-\mathrm{B}$ and $\mathrm{C}-\mathrm{D}$, respectively, in Figure $6 \mathrm{a}$ ). In contrast to the rapidly flowing glaciers previously described, this glacier allowed us to derive flow velocity data even near the terminus, likely because the slower flow velocities allowed the glacier to maintain its surface features over time. Figure $6 \mathrm{~b}$ summarizes the temporal evolution of mean velocities at each profile and the frontal position; temporal evolution of the velocity profile is shown in the supplementary material. While the velocities in the upstream were stable over time (C-D), those near the terminus in 2008-2010 have apparently increased by more than $200 \%$ over $2004-2005$. The near-terminus region apparently underwent a significant longitudinal stretching. We evaluated the frontal position retreat to be $\sim 2 \mathrm{~km}$ from 2004 to 2011 . However, the frontal positions at some epochs are missing because a vague image contrast prevented clear identification. Instead of a clear frontal position, we observed numerous icebergs that likely disintegrated from the terminus. The rate of terminus retreat accelerated from $55 \mathrm{~m} / \mathrm{a}$ for the period from 1986 to 2006 to $\sim 285 \mathrm{~m} / \mathrm{a}$ for the recent period from 2004 to 2011 . 


\subsection{Glacier Pio XI}

Glaciar Pio XI, the largest glacier in the SPI, flows to the west from a location near Volcán Lautaro (elevation $3380 \mathrm{~m}$ ) and bifurcates into two tongues to the north and south near its lower end, which flow into 'Lago Greve' and Eyre Fjord, respectively (Figure 7a); the southern front is thus a tidewater front. In contrast to the other glaciers in Patagonia that are rapidly retreating, Glaciar Pio XI was known for its significant terminus advances at both tongues during the 20th century (Warren and Rivera, 1994; Rivera et al., 1997). The front region is reportedly thickening at a rate of greater than $2 \mathrm{~m} / \mathrm{a}$ (Rivera and Casassa, 1999; Willis et al., 2012). On the basis of ground-based measurements recorded in November 1995, Rivera et al. (1997) reported maximum velocities of 17 to $50 \mathrm{~m}$ /day near the southern terminus. Although these faster velocities, in addition to the terminus advances, have led to an interpretation of a surging glacier, the factors controlling the dynamics of Glaciar Pio XI remain uncertain (Rivera et al., 1997). Apparently, this glacier has not been directly responding to the climate change (Warren and Rivera, 1994).

We selected three profiles across the northern tongue (A-B in Figure 7a), southern tongue $(\mathrm{C}-\mathrm{D}$ in Figure $7 \mathrm{a})$, and the main upstream region $(\mathrm{E}-\mathrm{F}$ in Figure 7a) to reveal the temporal evolution of the surface velocities. Figures $7 \mathrm{~b}-7 \mathrm{~d}$ summarize the temporal evolution of the mean surface velocities at each profile, and the frontal position changes at the northern and southern tongues from 2003 to 2011 are shown in Figures 7b and 7c. The temporal evolution of each velocity profile is shown in the supplementary material. The flow velocity in the main upstream was relatively stable over time, although 
it revealed deceleration in 2007 (Figure 7d). In contrast, the velocities at the northern and southern tongues were highly variable over time (Figures 7b and 7c). The southern tongue reveals faster signals in 2003, 2005, and 2007, when the velocities nearly doubled those in slower phases. While the northern tongue was slowly flowing at $0.2 \mathrm{~m} /$ day in 2003, it gradually accelerated and reached $2.0 \mathrm{~m} /$ day in 2007 . The upstream thus does not appear to directly control the flow velocities in the downstream.

Despite the highly variable velocity changes to the northern and southern tongues (Figures $7 \mathrm{~b}$ and $7 \mathrm{c}$ ), we did not observe any significant retreat as observed in Glaciars Upsala, Jorge Montt, and Occidental. Figure 8 includes the frontal positions over the analyzed period. While these positions have overall advanced from 2003 to 2011, we observed fluctuations in the front positions within a range of $\sim 250 \mathrm{~m}$ between advancing and retreating periods.

\section{Discussion and Conclusion}

Although the retreat and thinning of glaciers in the SPI over the past decades have been well-documented, we used SAR image analysis to demonstrate that not all of the examined glaciers revealed significant changes in frontal positions and flow velocities from 2002 to 2011. Moreover, even for such glaciers that underwent rapid retreat and acceleration, the terminus retreat and flow acceleration occurred sporadically rather than gradually over time, suggesting that positive-feedback processes promoted such movement. This finding was made possible through the use of SAR images that were free from cloud and night time problems, although more frequent image acquisitions are desirable. 
The observed rapid retreat and acceleration at Glaciars Upsala, Jorge Montt, and Occidental have important implications for calving mechanisms. In particular, despite the marked differences in absolute flow velocity among the three glaciers, the region toward the terminus at each glacier underwent significant acceleration, which was observed by calculating differences in the velocity map at two epochs (Figure 9). Figure 9 indicates larger velocity increments downstream, which demonstrates longitudinal stretching or extension toward the termini. Because longitudinal stretching is observed even at distances greater than $\sim 5 \mathrm{~km}$ upstream from the 2011 termini, the actual accelerations near the terminus regions of Glaciars Upsala and Jorge Montt will probably be much larger (Figures $9 \mathrm{a}$ and $9 \mathrm{~b}$ ). The near-terminus area in Glaciar Occidental flowed at a rate of $\sim 0.5 \mathrm{~m} /$ day by at least 2005 and began to accelerate in 2007, while the upstream velocities were stable. Such longitudinal stretching toward the terminus is clearly revealed at Glaciar Occidental (Figure 9c).

The observed longitudinal stretching at the rapidly retreating glaciers will contribute to increasing the crevasse-depths, and thus appears to support a calving model based on crevasse-depth criteria (Benn et al., 2007a, b; Nick et al., 2010), in which the absolute flow velocity itself is not critical. Benn et al. (2007b) proposed that longitudinal stretching due to the spatial velocity gradient, which determines the location and depth of surface crevasses, and the difference between ice thickness and water depth (effective pressure) are the primary controls for the frontal position of calving. This theory assumes that the basal sliding velocity is equal to the vertically averaged ice velocity. While Benn et al's model predicts the calving front position in which the 
depth of the surface crevasse equals the ice height above the water line, Nick et al. (2010) modified the model to predict calving for cases in which both surface and basal crevasses penetrate the full thickness of the glacier.

The longitudinal stretching and rapid terminus retreat at Glaciar Upsala, Jorge Montt, and Occidental can be regarded as indicators of the on-going dynamic thinning process. These three glaciers have been thinning over the past decade (Willis et al., 2012). Because the glacier thinning reduces the viscous ice velocity due to the decrease of gravitational force, we attribute the observed speed-up to the enhanced basal sliding velocity. We consider that the basal sliding enhancement is caused by the surface melt input and subsequent reduction of effective pressure due to the water pressure increase as observed at Greenland (e.g., Sundal et al., 2011). If the basal sliding velocity dominantly contributes to the vertically averaged velocity, the longitudinal stretching will also increase and allow the crevasses to penetrate further, causing the terminus to retreat up-glacier. As recognized from a bathymetric survey conducted at Glaciar Upsala (Naruse and Skvarca, 2000), this terminus retreat will likely be halted in shallower water because the effective pressure will increase. Such stabilization of the terminus retreat is, however, not simply controlled by the local water-depth or ice thickness as in the height-above-buoyancy model by Van der Veen (1996). Physics-based crevasse-depth calving criteria can eliminate the unrealistically large terminus retreats predicted from the height-above-buoyancy criterion (Nick et al., 2010).

Our observations suggest that even other seemingly stable glaciers between 2003 and 2011 may undergo rapid retreat and acceleration in the fu- 
ture. The Glaciar Occidental observation provides an important lesson for understanding the sporadic nature of calving processes. However, we cannot determine the point at which glaciers will undergo significant frontal retreat and acceleration in the future because calving processes involve a variety of unknown variables, which remain poorly understood (Benn et al., 2007a). Continuation of frequent surface velocity monitoring and combining the results with bathymetric and ice-thickness survey data can more precisely validate and refine the calving model, which may enable prediction of the initiation of dynamic-thinning.

The behavior of Glaciar Pio XI is enigmatic, and has been suggested as a surging type (Rivera et al., 1997). Transverse velocity profiles derived in this study indicate parabolic shapes with smaller velocities near the edge, which increase toward the center and do not exhibit the plug flow observed in other surging glaciers (Kamb et al., 1985; Murray et al., 2003; Yasuda and Furuya, 2013). However, note that the maximum water depths in front of the calving front at Eyre Fjord are $\sim 20 \mathrm{~m}$, and that those at Lago Greve are speculated to be much shallower than 150 m (Warren and Rivera, 1994). These water depths are significantly shallower than those at other glaciers, which may be attributed to the former surging episodes that should have transported a sufficient amount of sediments to raise the bottom depth of the fjord. While it appears unlikely that a rapid terminus retreat will begin in the near future, it is important to continue monitoring Glaciar Pio XI with the same frequency as that of other calving glaciers in the SPI.

It remains uncertain how much the total ice loss in the Patagonian Ice Fields is split into surface processes (runoff and precipitation) and ice dynam- 
ics, and the surface velocity data are indispensable to evaluate the contribution from ice dynamics. The velocities presented in this study are still not complete, because the velocities at the very front of the glaciers are missing. Because the missing velocities near the front are probably faster, the inferred ice velocities might be helpful to constrain the lower bound of ice discharge. Nonetheless, given the fact that not all the examined glaciers revealed acceleration and terminus retreat, the contribution from ice dynamics to the total ice loss might be not as high as those in Greenland, where widespread ice acceleration was observed (Joughin et al., 2008) and the partitioning ratio was shown to be equal (van den Broeke et al., 2009). In order to quantify the ice discharge, both surface mass balance and ice thickness data in the Patagonian Ice Fields are also necessary.

\section{Acknowledgements}

PALSAR level 1.0 data in this study were provided by the PALSAR Interferometry Consortium to Study our Evolving Land surface (PIXEL) and the ALOS 3rd PI project under cooperative research contracts with JAXA. The PALSAR data are owned by JAXA and the Ministry of Economy, Trade and Industry. Envisat data are copyrighted by ESA and were provided under Cat-1 project 9364. This study is partially supported by KAKENHI (24651001). We acknowledge two anonymous reviewers for their helpful and constructive comments. 


\section{References}

Andersen, P. H., K. Aksnes, \& H. Skonnord. (1998). Precise ERS-2 orbit determination using SLR, PRARE, and RA observations, J. Geodesy, 72(7/8), $421-429$

Aniya, M. \& P. Skvarca. (1992). Characteristics and variations of Upsala and moreno glaciers, southern patagonia, Bull. Glacier Res., 10, 39-53.

Aniya, M., H. Sato, R. Naruse, P. Skvarca, \& G. Casassa. (1996). The Use of Satellite and Airborne Imagery to Inventory Outlet Glaciers of the Southern Patagonia Icefield, South America, Photogramm. Eng. Remote Sens., 62(12), 1361-1369.

Aniya, M., H. Sato, R. Naruse, P Skvarca, \& G. Casassa. (1997). Recent Glacier Variations in the Southern Patagonia Icefield, South America, Arct. Alp. Res., 29, 1-12.

Benn, D. I., C. R. Warren, \& R. H. Mottram. (2007a). Calving processes and the dynamics of calving glaciers, Earth Sci. Rev., 82, 143-179, doi:10.1016/j.earscirev.2007.02.002.

Benn, D. I., N. R. J. Hulton, \& R. H. Mottram. (2007b). 'Calving laws', 'sliding laws' and the stability of tidewater glaciers, Ann. Glaciol. 46, 123130.

Bevan, S. L., T. Murray, A. J. Luckman, E. Hanna, \& P. Huybrechts. (2012). Stable dynamics in a Greenland tidewater glacier over 26 years despite reported thinning, Ann. Glaciol., 53(60), 241-248, doi: 10.3189//2102AoG60A076. 
Chen, J. L., C. R. Wilson, B. D. Tapley, D. D. Blankenship, \& E. R. Ivins. (2007). Patagonia Ice Field melting observed by Gravity Recovery and Climate Experiment (GRACE), Geophys. Res. Lett., 34, L22501, doi:10.1029/2007GL031871.

Ciappa, A., L. Pietranera, \& F. Battazza. (2010). Perito Moreno Glacier (Argentina) flow estimation by COSMO SkyMed sequence of high-resolution SAR-X imagery, Remote Sens. Environ., 114, 2088-2096.

Cuffey, K. M., \& W. S. B. Paterson. (2010). The Physics of Glaciers, 4th ed., Elsevier.

Delgado, S. (2009). GLIMS Glacier Database. Boulder, CO: National Snow and Ice Data Center/World Data Center for Glaciology. Digital Media.

Dickmann, N. (2007). GLIMS Glacier Database. Boulder, CO: National Snow and Ice Data Center/World Data Center for Glaciology. Digital Media. Floricioiu, D., M. Eineder, H. Rott, \& T. Nagler. (2008). Velocities of Major Outlet Glaciers of the Patagonia Icefield Observed by TerraSAR-X, Proc. IGARSS 2008, IV - 347 - IV - 350 , doi: 10.1109/IGARSS.2008.4779729.

Floricioiu, D., M. Eineder, H. Rott, N. Yague-Martinez, \& T. Nagler. (2009). Surface velocity and variations of outlet glaciers of the Patagonia Icefields by means of TerraSAR-X, Proc. IGARSS 2009, II - 1028 - II - 1031, doi: 10.1109/IGARSS.2009.5418279

Goldstein, R. M., H. Engelhardt, B. Kamb, \& R.M. Frolich. (1993). Satellite radar interferometry for monitoring ice sheet motion: application to an Antarctic ice stream, Science, 262 (5139), 1525-1530. 
Gourmelen, N., S. W. Kim, A. Shepherd, J. W. Park, A. V. Sundal, H. Björnsson, and F. Pálsson (2011), Ice velocity determined using conventional and multiple-aperture InSAR, Earth Planet. Sci. Lett., 307, 156-160, doi:10.1016/j.epsl.2011.04.026.

Holland, D. M., R. H. Thomas, B. de Young, M. H. Ribergaard, \& B. Lyberth. (2008). Acceleration of Jakobshavn Isbr triggered by warm subsurface ocean waters, Nat. Geosci., 1, 659-664, doi:10.1038/ngeo316.

Ivins, E. R., M. M. Watkins, D. N. Yuan, R. Dietrich, G. Casassa, \& A. Rülke. (2011). On-land ice loss and glacial isostatic adjustment at the Drake Passage; 2003-2009, J. Geophys. Res., 116, B02403, doi:10.1029/2010JB007607.

Jarvis A., H. I. Reuter, A. Nelson, \& E. Guevara. (2008). Hole-filled seamless SRTM data V4, International Centre for Tropical Agriculture (CIAT), available from http://srtm.csi.cgiar.org.

Jacob, T., J. Wahr, W. T. Pfeffer, \& S. Swenson. (2012). Recent contributions of glaciers and ice caps to sea level rise, Nature 482, 514-518, doi:10.1038/nature10847

JAXA. (2010). Significant retreats of huge glaciers in Patagonia, South America (Part 3). available at http://www.eorc.jaxa.jp/en/imgdata/topics/2010/tp100421.html

Joughin, I., R. Kwok, \& M. Fahnestock. (1996). Estimation of ice-sheet motion using satellite radar interferometry: Method and error analysis with application to Humboldt Glacier, Greenland, J. Glaciol., 42, 564-575. 
Joughin, I., S. B. Das, M. A. King, D. E. Smith, I. M. Howat, \& T. Moon. (2008). Seasonal Speedup Along the Western Flank of the Greenland Ice Sheet, Science, 320, 781-783, doi:10.1126/science.1153288

Kamb, B., C. F. Raymond, W. D. Harrison, H. Engelhardt, K. A. Echelmeyer, N. Humphrey, M. M. Brugman, \& T. Pfeffer. (1985). Glacier surge mechanism: 1982-1983 surge of Variegated Glacier, Alaska, Science, $227,469-479$.

Katagiri, S. \& Y. Yamamoto. (2008). Technology of precise orbit determination, Fujitsu Sci. Tech. J., 44(4), 401-409.

Kobayashi, T., T. Takada, M. Furuya, \& M. Murakami. (2009). Locations and types of ruptures involved in the 2008 Sichuan earthquake inferred from SAR image matching, Geophys. Res. Lett., 36, L07302, http://dx.doi.org/10.1029/2008GL036907.

Masiokas, M. (2009). GLIMS Glacier Database. Boulder, CO: National Snow and Ice Data Center/World Data Center for Glaciology. Digital Media.

Masiokas, M. (2010). GLIMS Glacier Database. Boulder, CO: National Snow and Ice Data Center/World Data Center for Glaciology. Digital Media.

Michel, R., J.-P. Avouac, \& J. Taboury. (1999). Measuring ground displacements from SAR amplitude images: Application to the Landers Earthquake, Geophys. Res. Lett., 26, 875-878. 
Michel, R., \& E. Rignot. (1999). Flow of Glacier Moreno, Argentina, from repeat-pass Shuttle Radar images: Comparison of the phase correlation method with radar interferometry, J. Glaciol., 45(149), 93-100.

Moon, T., \& I. Joughin. (2008). Changes in ice front position on Greenland's outlet glaciers from 1992 to 2007, J. Geophys. Res., 113, F02022, doi:10.1029/2007JF000927.

Moon,T., I. Joughin, B. Smith, \& I. Howat. (2012). 21st-Century Evolution of Greenland Outlet Glacier Velocities, Science, 336, 576-578, doi: 10.1126/science. 1219985

Murray, T., T. Strozzi, A. Luckman, H. Jiskoot, \& P. Christakos. (2003). Is there a single surge mechanism? Contrasts in dynamics between glacier surges in Svalbard and other regions, J. Geophys. Res., 108, B52237, doi:10.1029/2002JB001906.

Naruse, R., P. Skvarca, T, Kadota, \& K. Koizumi. (1992). Flow of Upsala and Moreno Glaciers, southern Patagonia, Bull. Glacier Res., 10, 55-62.

Naruse, R., P. Skvarca, K. Satow, Y. Takeuchi, \& K. Nishida. (1995). Thickness change and short-term flow variation of Moreno Glacier, Patagonia. Bull. Glacier Res., 13, 21-28.

Naruse, R., P. Skvarca, \& Y. Takeuchi. (1997). Thinning and retreat of Glaciar Upsala, and an estimate of annual ablation changes in southern Patagonia, Ann. Glaciol., 24, 38-42. 
Naruse, R., \& P. Skvarca. (2000). Dynamic Features of Thinning and Retreating Glaciar Upsala, a Lacustrine Calving Glacier in Southern Patagonia, Arct. Antarct. Alp. Res., 32(4), 485-491.

Nick, F. M., C. J. van der Veen, A, Vieli, \& D. I. Benn. (2010). A physically based calving model applied to marine outlet glaciers and implications for the glacier dynamics, J. Glaciol., 56, 781-794, doi:10.3189/002214310794457344.

Pritchard, H. D., R. J. Arthern, D. G. Vaughan \& L. A. Edwards. (2009), Extensive dynamic thinning on the margins of the Greenland and Antarctic ice sheets, Nature, 461, 971-975, doi:10.1038/nature08471.

Rignot, E., A. Rivera, \& G. Casassa. (2003). Contribution of the Patagonia Icefields of South America to Sea Level Rise, Science, 302 (5644), 434-437.

Rignot, E. \& P. Kanagaratnam. (2006). Changes in the Velocity Structure of the Greenland Ice Sheet, Science, 311, 986-990, doi: 10.1126/science. 1121381

Rignot, E. (2008). Changes in West Antarctic ice stream dynamics observed with ALOS PALSAR data, Geophys. Res. Lett., 35, L12505, doi:10.1029/2008GL033365.

Rignot, E., M. Koppes, \& I. Velicogna. (2010). Rapid submarine melting of the calving faces of West Greenland glaciers. Nat. Geosci., 3, 187-191, doi:10.1038/ngeo765.

Rivera, A. \& Casassa, G. (1999). Volume changes on Pio XI glacier, Patagonia: 1975-1995, Global Planet. Change, 22, 233-244 
Rivera, A., H. Lange,J. C. Aravena, \& G. Casassa. (1997). The 20th-century advance of Glacier Pio XI, Chilean Patagonia, Ann. Glaciol., 24, 66-71

Rivera, A., J. Corripio, C. Bravo, \& S. Cisternas. (2012a). Glaciar Jorge Montt (Chilean Patagonia) dynamics derived from photos obtained by fixed cameras and satellite image feature tracking, Ann. Glaciol., 53(60), 147-155, doi:10.3189/2012AoG60A152.

Rivera, A., M. Koppes, C. Bravo, \& J. C. Aravena. (2012b). Little Ice Age advance and retreat of Glaciar Jorge Montt, Chilean Patagonia, Clim. Past, 8, 403-414, doi:10.5194/cp-8-403-2012

Rott, H., M. Stuefer, A. Siegel, P. Skvarca, \& A. Eckstaller. (1998). Mass fluxes and dynamics of Moreno Glacier, Southern Patagonia Icefield, Geophys. Res. Lett., 25(9), 1407-1410.

Sakakibara, D., S. Sugiyama, T. Sawagaki, S. Marinsek, \& P. Skvarca. (2013). Rapid retreat, acceleration and thinning of Glaciar Upsala, Southern Patagonia Icefield, initiated in 2008, Ann. Glaciol., 54(63), 131-138, doi:10.3189/2013AoG63A236.

Sansosti, E., P. Berardino, M. Manunta, F. Serafino, \& G. Fornaro. (2006). Geometrical SAR Image Registration, IEEE Trans. Geosci. Rem. Sens., 44(10), 2861-2870.

Scharroo, R \& P. Visser. (1998). Precise orbit determination and gravity eld improvement for the ERS satellites, J. Geophys. Res., 103(C4), 8113-8128 Skvarca, P., K. Satow, R. Naruse \& J.C. Leiva. (1995). Recent thinning, retreat and flow of Upsala Glacier, Patagonia, Bull. Glacier Res., 13, 11-20. 
Skvarca, P., B. Raup, \& H. De Angelis. (2002). Calving rates in fresh water: new data from southern Patagonia, Ann. Glaciol., 34, 379-384.

Skvarca, P., B. Raup, \& H. De Angelis. (2003). Recent behaviour of Glacier Upsala, a fast-flowing calving glacier in Lago Argentino, southern Patagonia, Ann. Glaciol., 36, 184-188.

Straneo, F., R. G. Curry, D. A. Sutherland, G. S. Hamilton, C. Cenedese, K. Vge \& L.A. Stearns. (2011). Impact of fjord dynamics and glacial runoff on the circulation near Helheim Glacier, Nat. Geosci., 4, 322-327, doi:10.1038/ngeo1109

Strozzi, T., A. Luckman, T. Murray, U. Wegmüller, \& C. Werner. (2002). Glacier motion estimation using SAR offset-tracking procedures, IEEE Trans. Geosci. Rem. Sens., 40(11), 2384-2391.

Strozzi, T., A. Kouraev, A. Wiesmann, U. Wegmüller, A. Sharov, and C. L. Werner (2008), Estimation of Arctic glacier motion with satellite L-band SAR data, Remote Sens. Environ., 112, 636-645.

Stueffer, M., H. Rott, \& P. Skvarca. (2007). Glaciar Perito Moreno, Patagonia: climate sensitivities and glacier characteristics preceding the 2003/04 and 2005/06 damming events, J. Glaciol., 53(180), 3-16.

Sugiyama, S., P. Skvarca, N. Naito, H. Enomoto, S. Tsutaki, K. Tone, S. Marinsek, \& M. Aniya. (2011). Ice speed of a calving glacier modulated by small fluctuations in basal water pressure, Nat. Geosci., 4, 597-600, doi://10.1038/ngeo1218. 
Sundal, A. V. et al. (2011), Melt-induced speed-up of Greenland ice sheet offset by efficient subglacial drainage, Nature, 469, 521-524, doi: 10.1038 /nature09740.

Warren, C., \& A. Rivera. (1994). Non-linear climatic response of Calving Glaciers: A case study of Pio XI Glacier, Chilean Patagonia, Revista Chilena de Historia Natural, 67, 385-394.

Warren, C., \& M. Aniya. (1999). The calving glaciers of southern South America, Global Planet. Change, 22, 59-77.

Willis, M. J., A. K. Melkonian, M. E. Pritchard, \& A. Rivera. (2012). Ice loss from the Southern Patagonian Ice Field, South America, between 2000 and 2012, Geophys. Res. Lett., 39, L17501, doi:10.1029/2012GL053136.

van den Broeke, M., J. Bamber, J. Ettema, R. Rignot, E. Schrama, W. J. van de Berg, E. van Meijgaard, I. Velicogna, \& B. Wouters. (2009). Partitioning Recent Greenland Mass Loss, Science, 326, 984-986, doi: 10.1126/science. 1178176

van der Veen, C. J. (1996). Tidewater calving. J. Glaciol., 42(141), 375-385. Yasuda, T., \& M. Furuya. (2013). Short-term glacier velocity changes at West Kunlun Shan, Northwest Tibet, detected by Synthetic Aperture Radar data, Remote Sens. Environ., 128, 87-106, doi: 10.1016/j.rse.2012.09.021. 
Figure 1: Elevation map of the studied area and the glaciers in the South Patagonian Icefield; the elevation data set was obtained NASA's Shuttle Radar Topography Mission (SRTM). Red triangles represent the termini of the eight analyzed glaciers. Blue and lightblue indicate fjord and proglacial lakes, respectively. Glacier outlines were determined on the basis of the Global Land Ice Measurements from Space (GLIMS) dataset, which is available through the US National Snow and Ice Data Center (Dickman, 2007; Delgado, 2009; Masiokas, 2009, 2010; Davies, 2012).

Figure 2: (a) Spatial distribution of surface flow velocities at Glaciar Upsala, derived from PALSAR images obtained on January 4 and February 19, 2011. (b) Temporal changes in the average frontal position and velocities at sites A and B depicted in (a).

Figure 3: Temporal evolution of the frontal position at Glaciar Upsala between 2002 and 2011. Background is a PALSAR-based scattering intensity image acquired on February 19, 2011.

Figure 4: (a) Spatial distribution of surface flow velocities at Glaciar Jorge Montt, derived from PALSAR images obtained on January 11 and February 26, 2008. (b) Temporal changes in the average frontal position and velocities at profile $\mathrm{A}-\mathrm{B}$ and site $\mathrm{C}$ in (a).

Figure 5: Temporal evolution of the frontal position at Glaciar Jorge Montt between 2002 and 2011. Background is a PALSAR-based scattering intensity image acquired on February 19, 2011.

Figure 6: (a) Spatial distribution of surface flow velocities at Glaciar Occidental, derived from PALSAR images obtained on January 4 and February 19, 2011. (b) Temporal changes in the average frontal position and velocities at profile $\mathrm{A}-\mathrm{B}$ and site $\mathrm{C}-\mathrm{D}$ in (a). 
Figure 7: (a) Spatial distribution of surface flow velocities at Glaciar Pio XI, derived from PALSAR images obtained on January 4 and February 19, 2011. Temporal evolution in the average velocity at each of the three profiles $(\mathrm{A}-\mathrm{B}, \mathrm{C}-\mathrm{D}$, and $\mathrm{E}-\mathrm{F})$ is shown in $(\mathrm{b}-\mathrm{d})$. (b) Temporal changes in the average frontal position and velocity across profile $\mathrm{A}-\mathrm{B}$ in the northern tongue. (c) Temporal changes in the average frontal position and velocity across profile $\mathrm{C}-\mathrm{D}$ in the southern tongue. (d) Temporal changes in the average velocity across profile $\mathrm{E}-\mathrm{F}$ in the main upstream.

Figure 8: Temporal evolution of the frontal position at Glaciar Pio XI between 2002 and 2011. Background is a PALSAR-based scattering intensity image acquired on February 19, 2011.

Figure 9: Velocity increases observed at (a) Glaciar Upsala from January 2003 to January 2011, (b) Glaciar Jorge Montt from January 2003 to January 2011, and (c) Glaciar Occidental from January 2003 to January 2011. 
Table 1: The processed SAR images

\begin{tabular}{|c|c|c|c|c|c|}
\hline Sensor & Path (Track) & Frame & Acquisition date & Mode & $\mathrm{A} / \mathrm{D}$ \\
\hline \multirow{20}{*}{ PALSAR } & 129 & 6150 & 20100216 & FBS & $\mathrm{A}$ \\
\hline & 129 & $6150,6160,6170,6180$ & 20100519 & FBD & $\mathrm{A}$ \\
\hline & 129 & $6150,6160,6170,6180$ & 20100704 & FBD & $\mathrm{A}$ \\
\hline & 129 & $6150,6160,6170,6180$ & 20110104 & FBS & $\mathrm{A}$ \\
\hline & 129 & $6150,6160,6170,6180$ & 20110219 & FBS & $\mathrm{A}$ \\
\hline & 130 & $6150,6160,6170,6180$ & 20100605 & FBD & $\mathrm{A}$ \\
\hline & 130 & $6150,6160,6170,6180$ & 20100721 & FBD & $\mathrm{A}$ \\
\hline & 130 & 6150 & 20101021 & FBD & $\mathrm{A}$ \\
\hline & 130 & 6150 & 20110121 & FBS & $\mathrm{A}$ \\
\hline & 410 & 4650 & 20070619 & FBD & $\mathrm{D}$ \\
\hline & 410 & 4650 & 20070919 & $\mathrm{FBD}$ & $\mathrm{D}$ \\
\hline & 410 & 4650 & 20071104 & FBD & $\mathrm{D}$ \\
\hline & 410 & 4650 & 20071220 & FBS & $\mathrm{D}$ \\
\hline & 411 & 4650 & 20070706 & FBD & $\mathrm{D}$ \\
\hline & 411 & 4650 & 20071121 & FBD & $\mathrm{D}$ \\
\hline & 411 & 4650 & 20080106 & FBS & $\mathrm{D}$ \\
\hline & 414 & 4600,4620 & 20070826 & FBD & $\mathrm{D}$ \\
\hline & 414 & 4600,4620 & 20071011 & FBD & $\mathrm{D}$ \\
\hline & 414 & 4600,4620 & 20080111 & FBS & $\mathrm{D}$ \\
\hline & 414 & 4600,4620 & 20080226 & FBS & $\mathrm{D}$ \\
\hline \multirow[t]{5}{*}{ ASAR } & 153 & $4599,4617,4635$ & 20021220 & $\mathrm{I} 2$ & $\mathrm{D}$ \\
\hline & 153 & $4599,4617,4635$ & 20030228 & $\mathrm{I} 2$ & $\mathrm{D}$ \\
\hline & 153 & $4599,4617,4635$ & 20030613 & $\mathrm{I} 2$ & $\mathrm{D}$ \\
\hline & 153 & $4599,4617,4635$ & 20030718 & $\mathrm{I} 2$ & $\mathrm{D}$ \\
\hline & 153 & $4599,4617,4635$ & 20030926 & $\mathrm{I} 2$ & $\mathrm{D}$ \\
\hline
\end{tabular}


(continued)

\begin{tabular}{|c|c|c|c|c|c|}
\hline Sensor & Path (Track) & Frame & Acquisition date & Mode & $\mathrm{A} / \mathrm{D}$ \\
\hline & 153 & $4599,4617,4635$ & 20031205 & $\mathrm{I} 2$ & $\mathrm{D}$ \\
\hline & 153 & $4599,4617,4635$ & 20040109 & $\mathrm{I} 2$ & $\mathrm{D}$ \\
\hline & 153 & $4599,4617,4635$ & 20040910 & $\mathrm{I} 2$ & $\mathrm{D}$ \\
\hline & 153 & $4599,4617,4635$ & 20050722 & $\mathrm{I} 2$ & $\mathrm{D}$ \\
\hline & 153 & $4599,4617,4635$ & 20050826 & $\mathrm{I} 2$ & $\mathrm{D}$ \\
\hline & 153 & $4599,4617,4635$ & 20080815 & $\mathrm{I} 2$ & $\mathrm{D}$ \\
\hline & 196 & 4599 & 20021223 & $\mathrm{I} 2$ & $\mathrm{D}$ \\
\hline & 196 & 4599 & 20030616 & $\mathrm{I} 2$ & $\mathrm{D}$ \\
\hline & 196 & 4599 & 20031208 & $\mathrm{I} 2$ & $\mathrm{D}$ \\
\hline & 196 & 4599 & 20040122 & $\mathrm{I} 2$ & $\mathrm{D}$ \\
\hline & 196 & 4599 & 20040322 & $\mathrm{I} 2$ & $\mathrm{D}$ \\
\hline & 196 & 4599 & 20040426 & $\mathrm{I} 2$ & $\mathrm{D}$ \\
\hline & 196 & 4599 & 20040531 & $\mathrm{I} 2$ & $\mathrm{D}$ \\
\hline & 196 & 4599 & 20040913 & $\mathrm{I} 2$ & $\mathrm{D}$ \\
\hline & 196 & 4599 & 20050620 & $\mathrm{I} 2$ & $\mathrm{D}$ \\
\hline & 196 & 4599 & 20050829 & $\mathrm{I} 2$ & $\mathrm{D}$ \\
\hline & 196 & 4599 & 20051003 & $\mathrm{I} 2$ & $\mathrm{D}$ \\
\hline & 196 & 4599 & 20070730 & $\mathrm{I} 2$ & $\mathrm{D}$ \\
\hline & 376 & 6147 & 20050703 & I6 & $\mathrm{A}$ \\
\hline & 376 & 6147 & 20050807 & I6 & $\mathrm{A}$ \\
\hline & 376 & 6147 & 20050911 & I6 & $\mathrm{A}$ \\
\hline & 382 & 4635 & 20030629 & $\mathrm{I} 2$ & $\mathrm{D}$ \\
\hline & 382 & 4635 & 20030803 & I2 & $\mathrm{D}$ \\
\hline & 382 & 4635 & 20040125 & I2 & $\mathrm{D}$ \\
\hline & 382 & 4635 & 20040229 & $\mathrm{I} 2$ & $\mathrm{D}$ \\
\hline & 382 & 4635 & 20040404 & $\mathrm{I} 2$ & $\mathrm{D}$ \\
\hline
\end{tabular}


(continued)

\begin{tabular}{cccccc}
\hline \multicolumn{5}{c}{$($ continued $)$} \\
\hline Sensor & Path (Track) & Frame & Acquisition date & Mode & A/D \\
\hline 382 & 4635 & 20040509 & I2 & D \\
382 & 4635 & 20040613 & I2 & D \\
425 & 4599,4617 & 20030108 & I2 & D \\
425 & 4599,4617 & 20030212 & I2 & D \\
425 & 4599,4617 & 20030423 & I2 & D \\
425 & 4599,4617 & 20030702 & I2 & D \\
425 & 4599,4617 & 20031015 & I2 & D \\
425 & 4599,4617 & 20040407 & I2 & D \\
425 & 4599,4617 & 20040512 & I2 & D \\
425 & 4599,4617 & 20040825 & I2 & D \\
425 & 4599,4617 & 20080903 & I2 & D \\
\hline
\end{tabular}

Table 2: The imaging angles and offsets as a function of 3-D displacements

\begin{tabular}{clllcc}
\hline Sensor & Mode (A/D) & $H$ (deg.) & $I$ (deg.) & $U_{r a}$ & $U_{a z}$ \\
\hline PALSAR & A & -20 & 39 & $0.59 U_{e}+0.22 U_{n}-0.78 U_{z}$ & $-0.34 U_{e}+0.94 U_{n}$ \\
PALSAR & D & -159 & 39 & $-0.59 U_{e}+0.22 U_{n}-0.78 U_{z}$ & $-0.36 U_{e}-0.93 U_{n}$ \\
ASAR & IS6 (A) & -22 & 41 & $0.61 U_{e}+0.25 U_{n}-0.75 U_{z}$ & $-0.37 U_{e}+0.93 U_{n}$ \\
ASAR & IS2 (D) & -162 & 23 & $-0.37 U_{e}+0.12 U_{n}-0.92 U_{z}$ & $-0.31 U_{e}-0.95 U_{n}$ \\
\hline
\end{tabular}


Supplementary material for "Surface Velocities and Ice-Front Positions of Eight Major Glaciers in the Southern Patagonian Ice Field, South America, from 2003 to 2011" by Minami Muto and Masato Furuya

We examined the surface velocity and frontal position evolution at eight glaciers in South Patagonian Ice Field, and showed in the main text the results of four glaciers that indicated significant temporal changes. With the exceptions of Glacier Upsala and the site C at Glacier Jorge Montt, we first selected five velocity profiles at nearly the same location across the flow direction of each glacier, and then derived an average and standard deviation of them as a measurement error.

The supplementary figures show temporal changes in the average frontal position and average velocities for the four glaciers not shown in the main text. In addition, the temporal changes of each velocity profile and standard deviation are also shown at the seven glaciers with the exception of Glacier Upsala. 


\section{Glacier Perito Moreno}

(a)

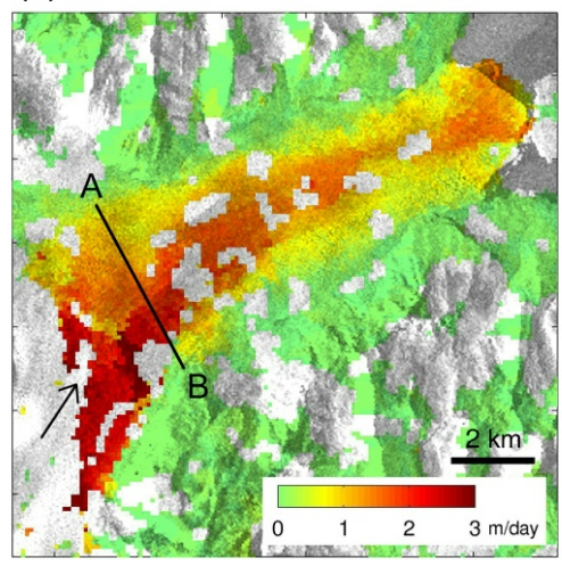

(b)

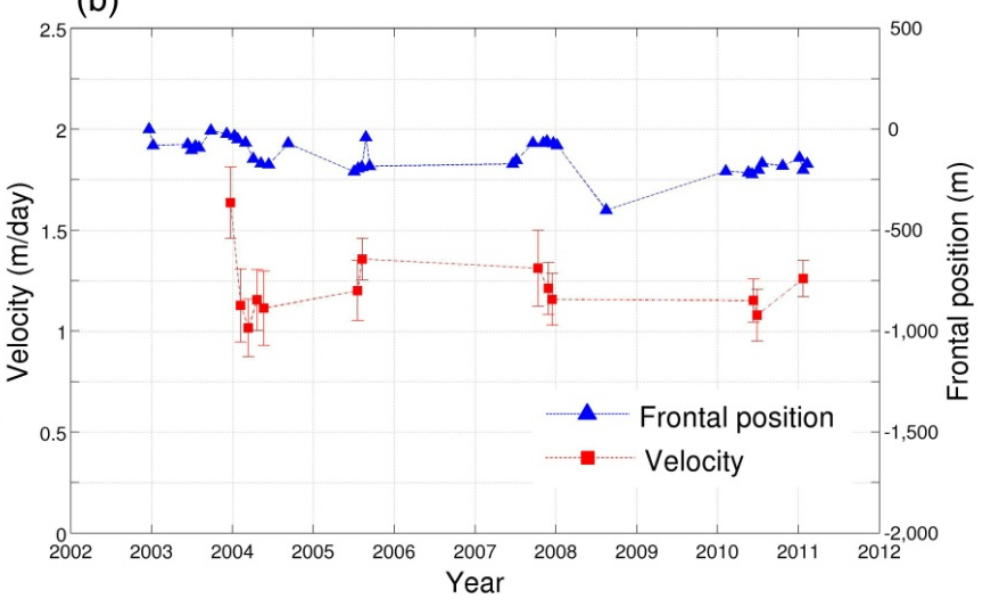

Figure S1: (a) Spatial distribution of surface flow velocities at Glacier Perito Moreno, derived from ASAR images obtained on July 3 and August 7, 2005. (b) Temporal changes in the average frontal position and velocities at profile A-B.

(a)

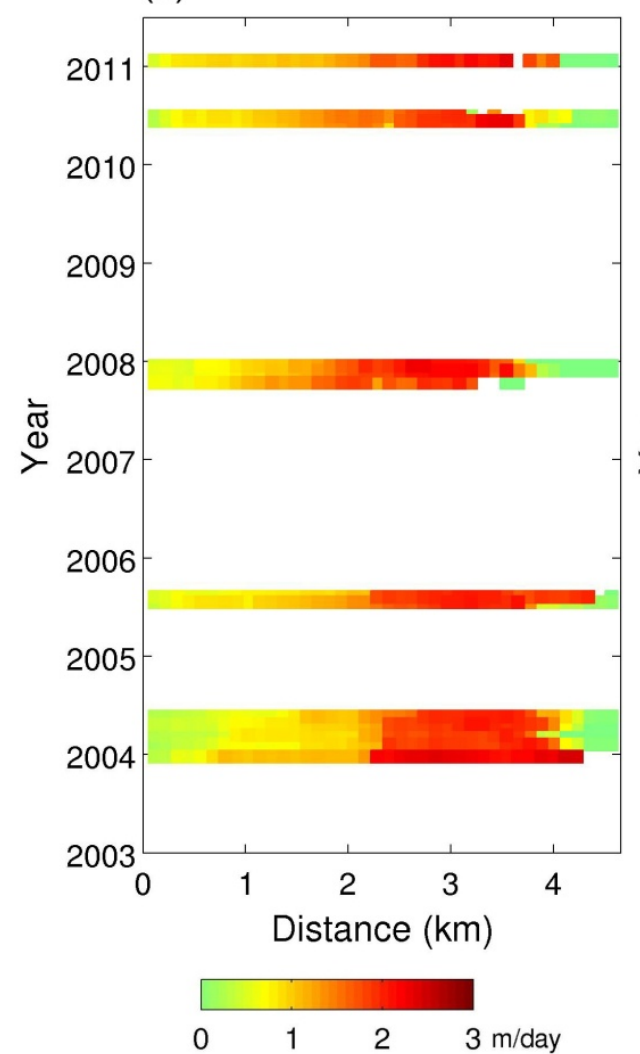

(b)

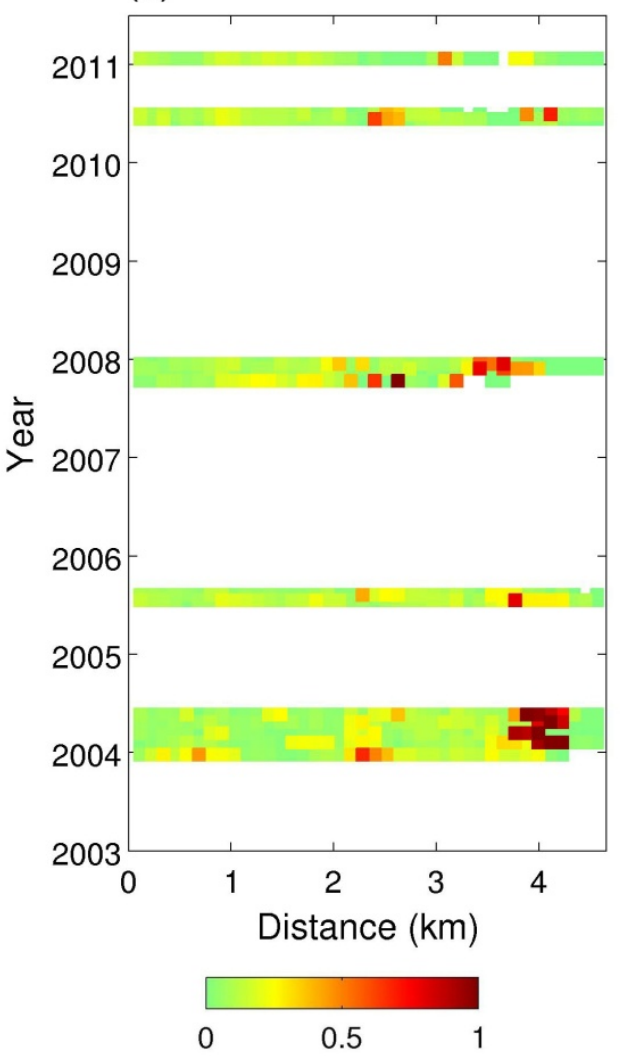

Figure S2: (a) Temporal evolution of the velocity profile A-B in Figure S1. (b) Estimated errors of the velocity profile at each epoch. 


\section{Glacier O’Higgins}

(a)

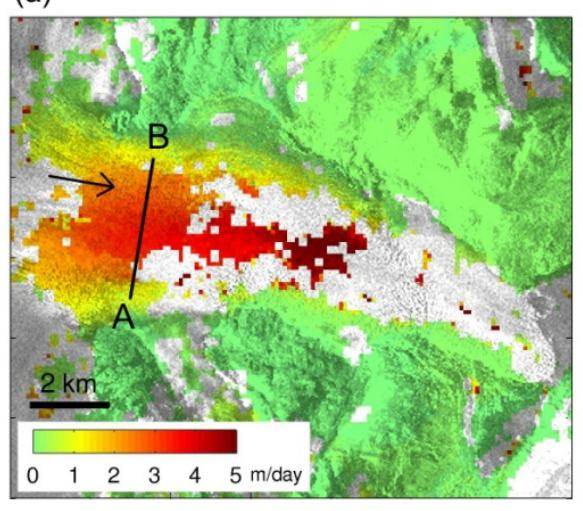

(b)

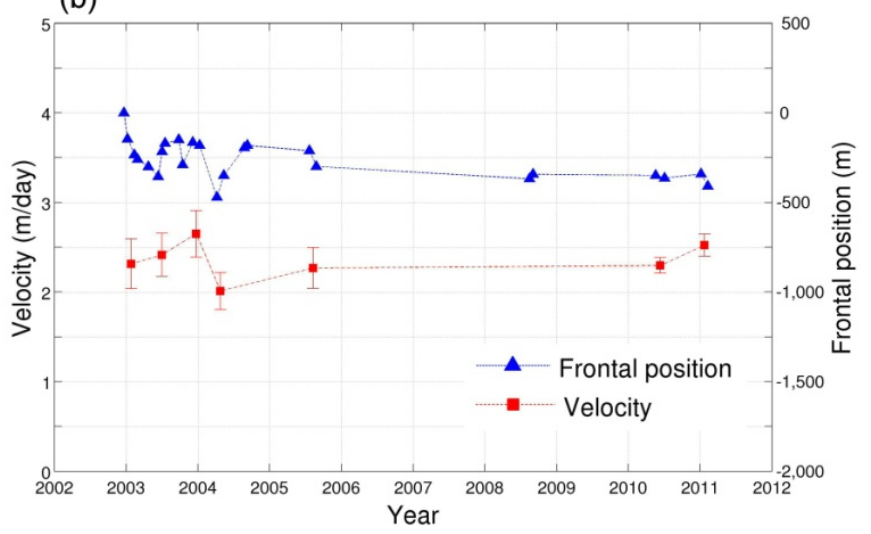

Figure S3: (a) Spatial distribution of surface flow velocities at Glacier O’Higgins, derived from PALSAR images obtained on January 4 and February 19, 2011. (b) Temporal changes in the average frontal position and velocities at profile A-B.

(a)

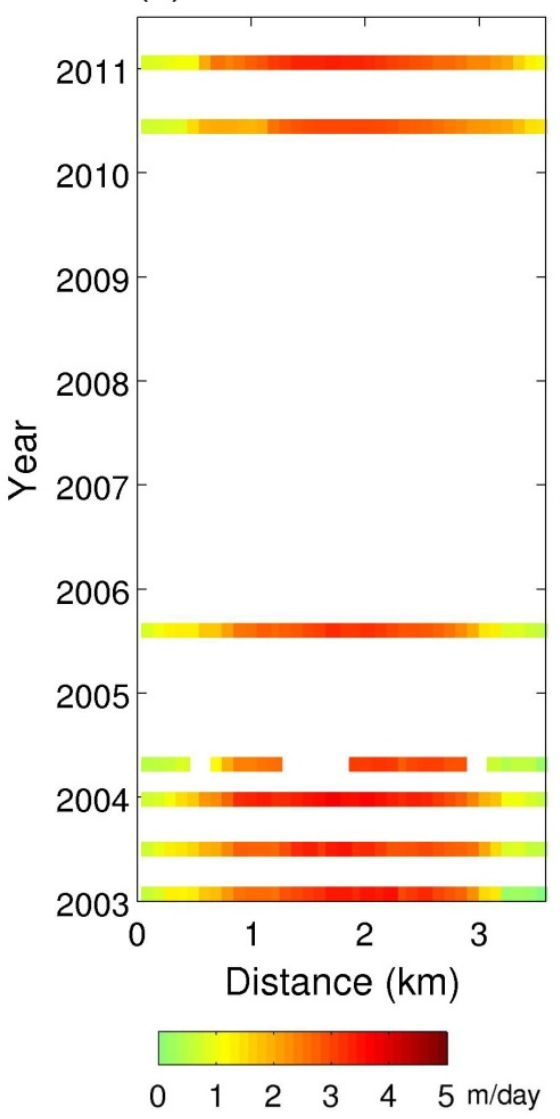

(b)

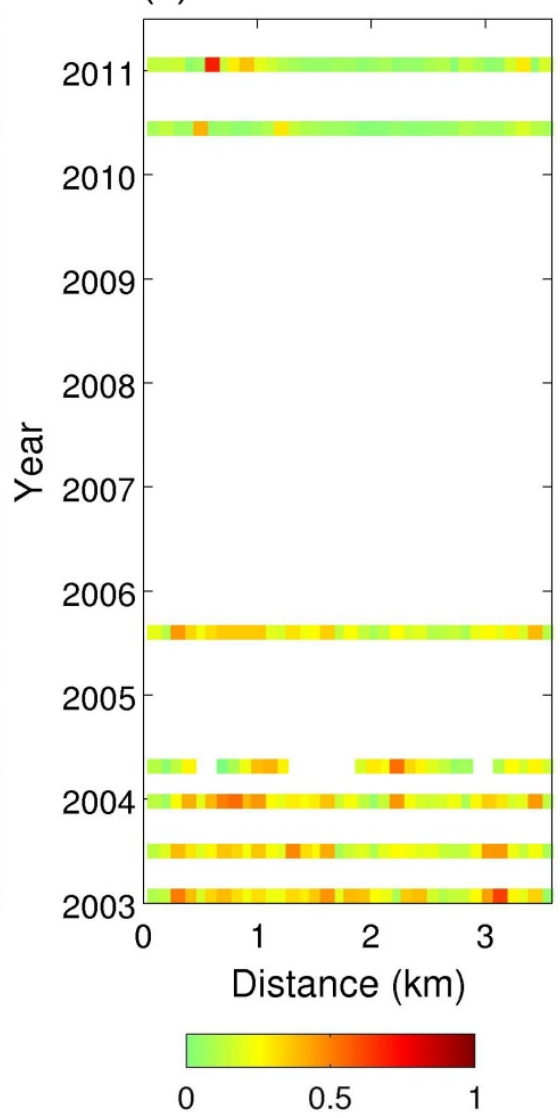

Figure S4: (a) Temporal evolution of the velocity profile A-B in Figure S3. (b) Estimated errors of the velocity profile at each epoch. 


\section{Glacier Viedma}

(a)

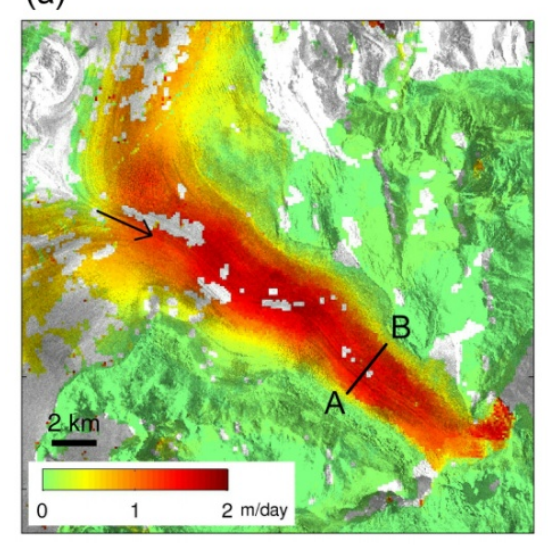

(b)

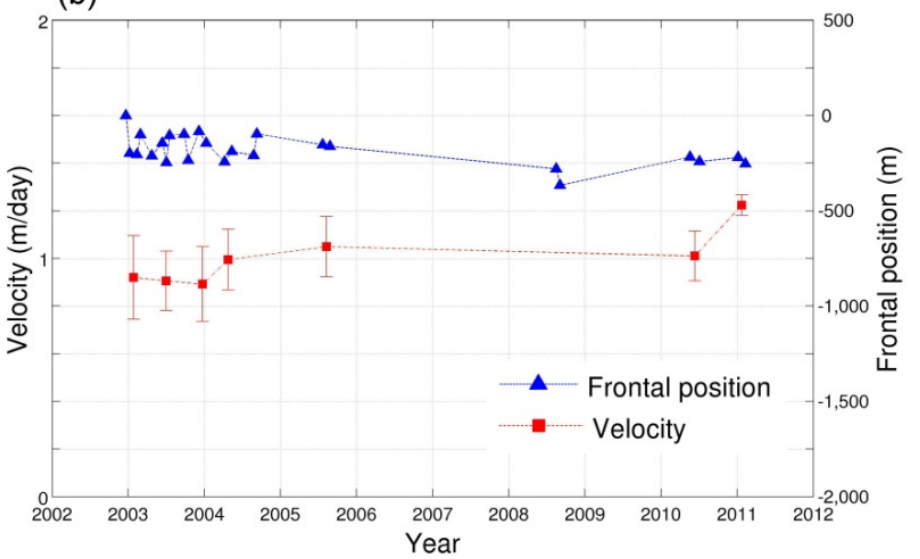

Figure S5: (a) Spatial distribution of surface flow velocities at Glacier Viedma, derived from PALSAR images obtained on January 4 and February 19, 2011. (b) Temporal changes in the average frontal position and velocities at profile A-B.

(a)

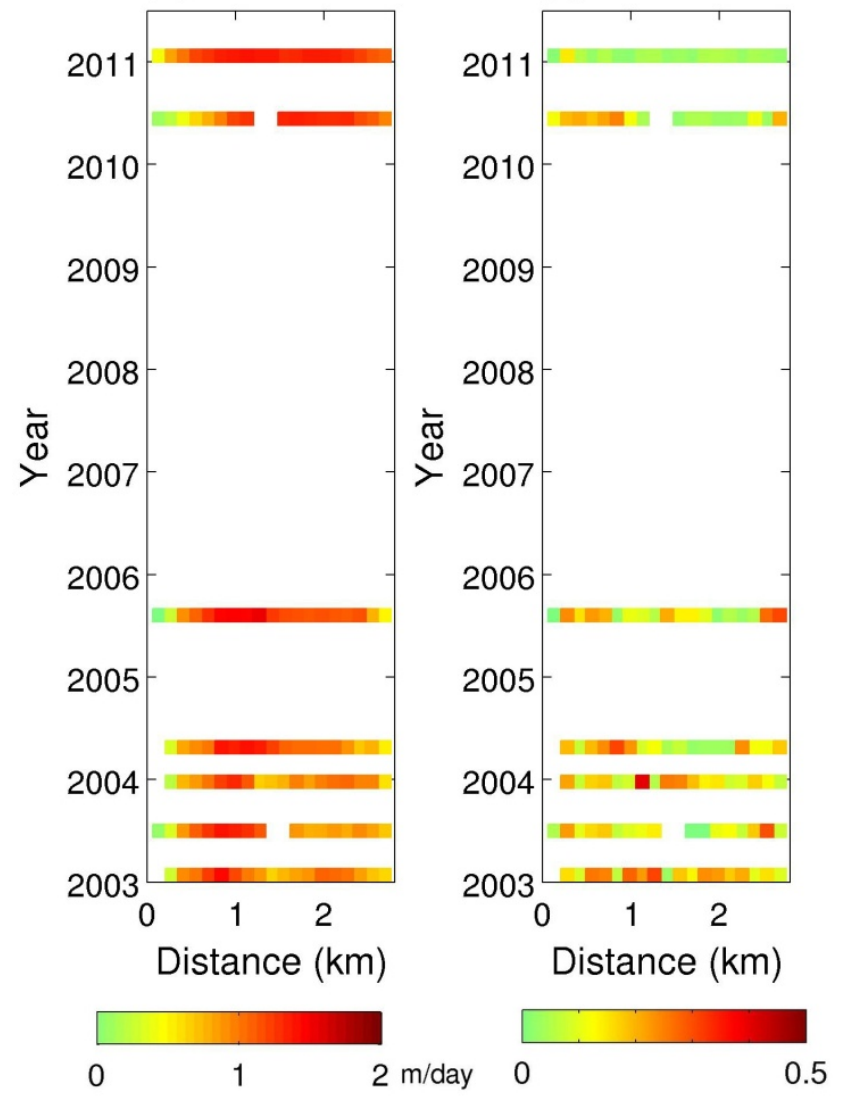

Figure S6: (a) Temporal evolution of the velocity profile A-B in Figure S5. (b) Estimated errors of the velocity profile at each epoch. 


\section{Glacier Grey}

(a)

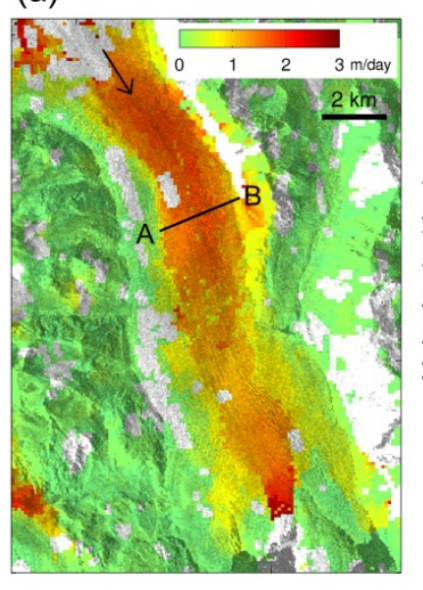

(b)

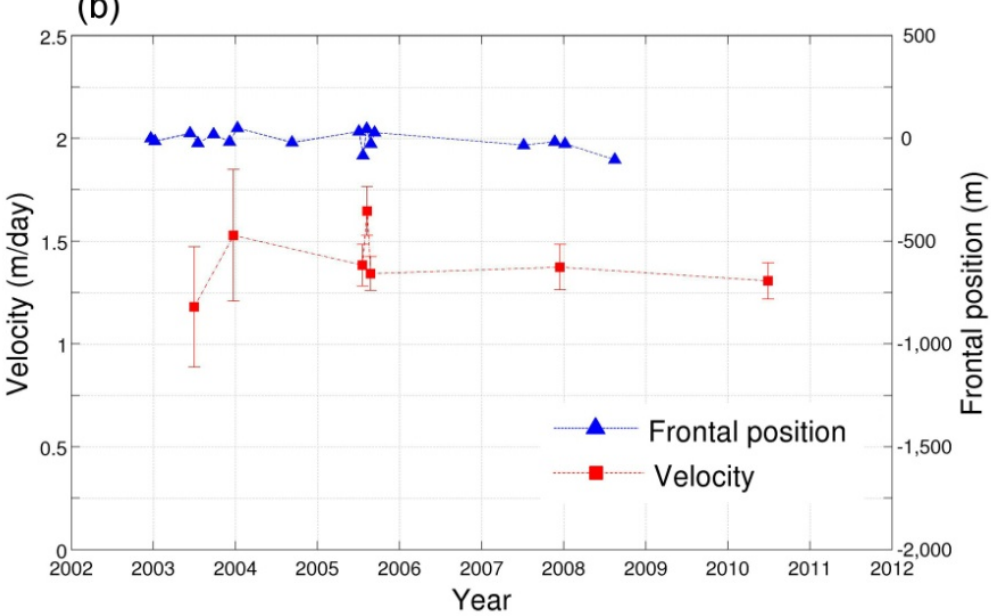

Figure S7: (a) Spatial distribution of surface flow velocities at Glacier Grey, derived from ASAR images obtained on July 3 and August 7, 2005. (b) Temporal changes in the average frontal position and velocities at profile A-B.

(a)

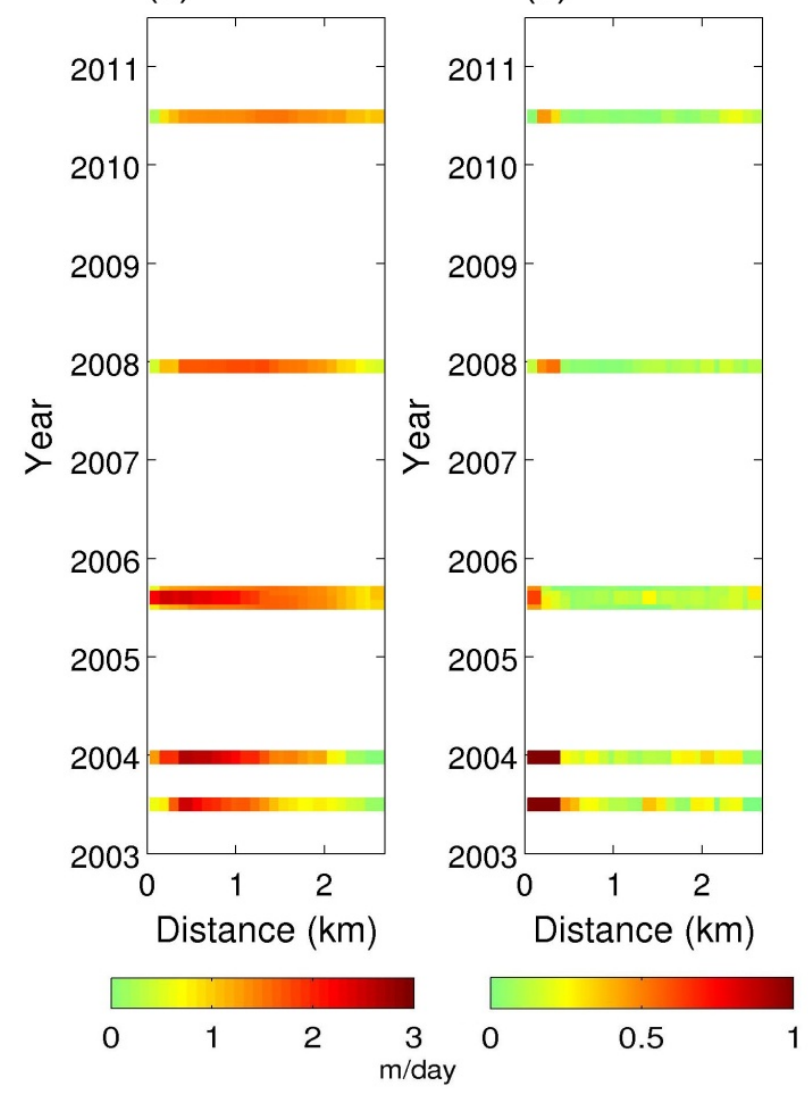

Figure S8: (a) Temporal evolution of the velocity profile A-B in Figure S7. (b) Estimated errors of the velocity profile at each epoch. 


\section{Glacier Jorge Montt}

(a)

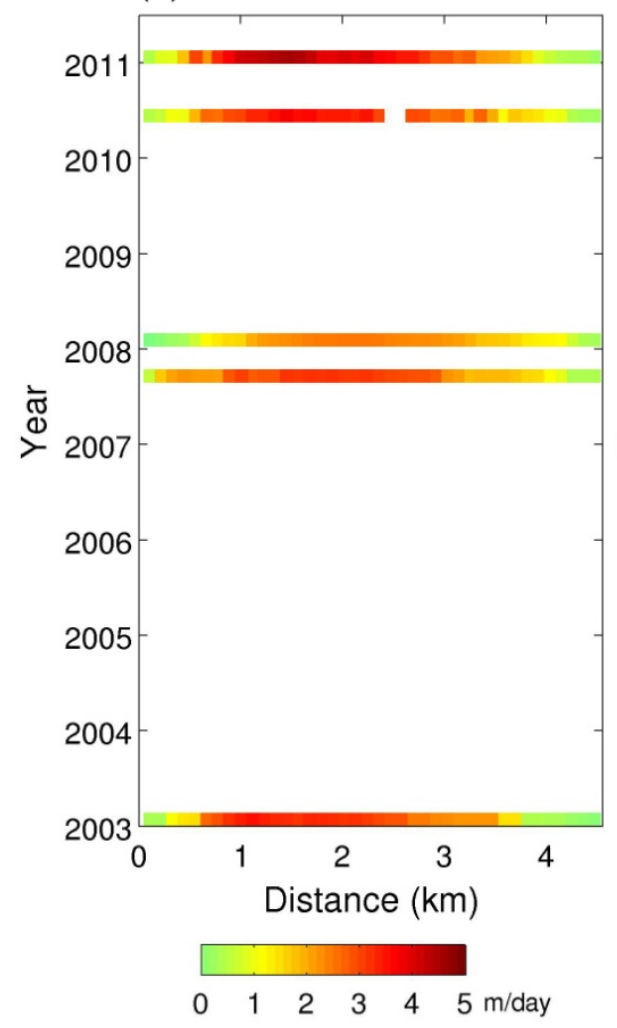

(b)

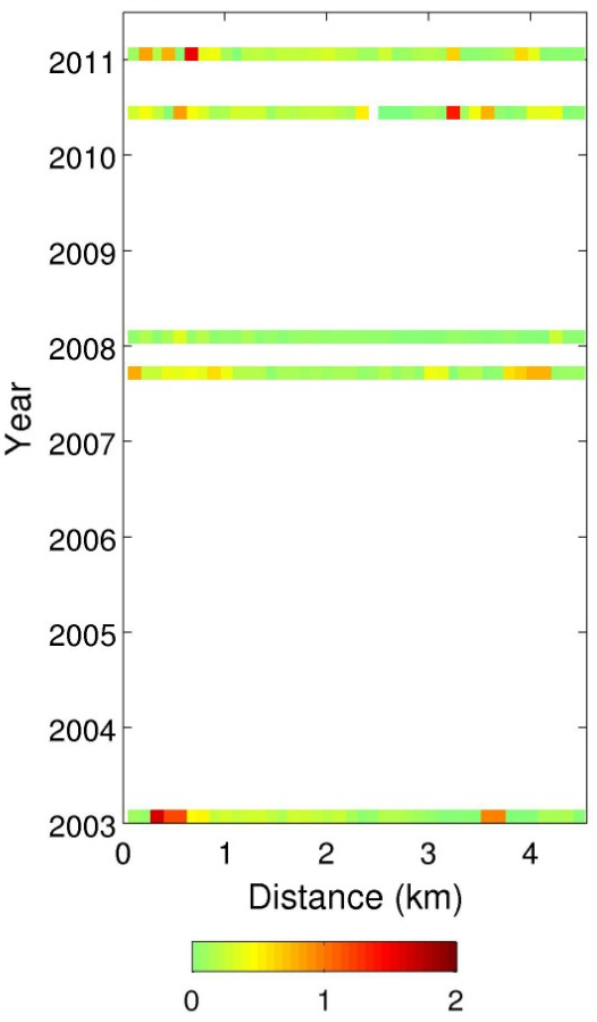

Figure S9: (a) Temporal evolution of the velocity profile A-B in Figure 4 in the main text. (b) Estimated errors of the velocity profile at each epoch. 


\section{Glacier Occidental}

(a)

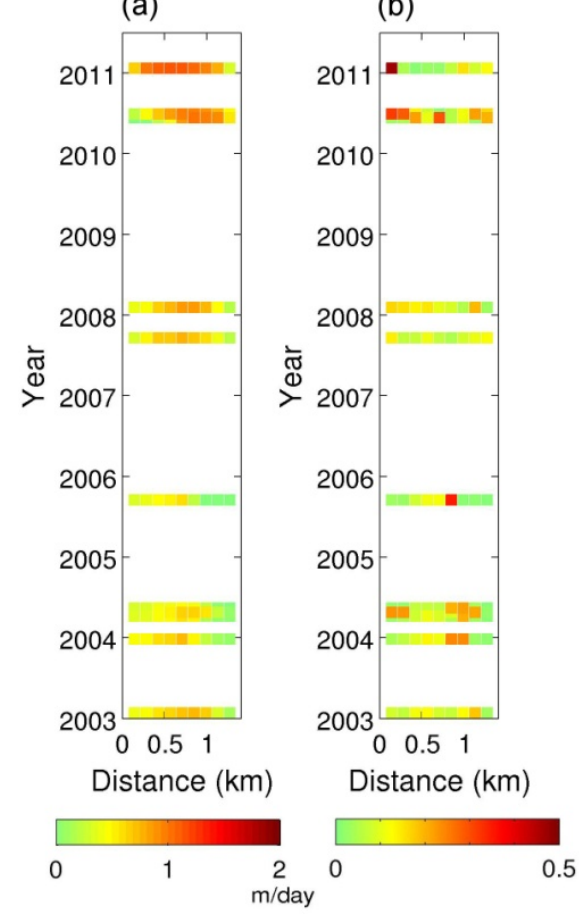

Figure S10: (a) Temporal evolution of the velocity profile A-B in Figure 6 in the main text. (b) Estimated errors of the velocity profile at each epoch.

(a)

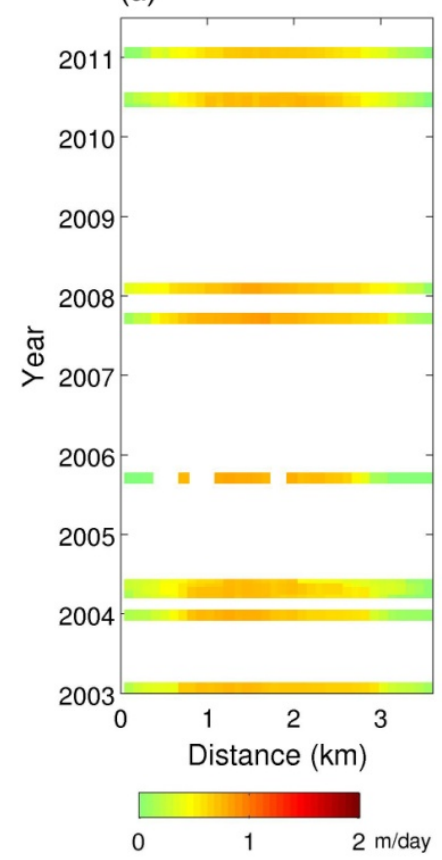

(b)

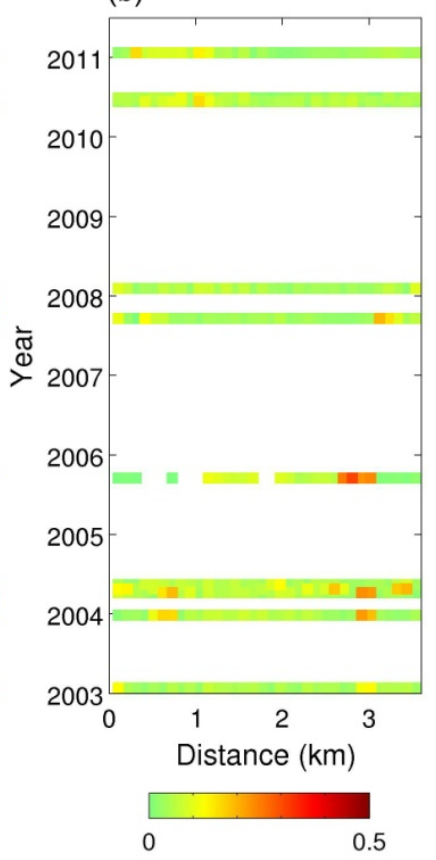

Figure S11: (a) Temporal evolution of the velocity profile C-D in Figure 6 in the main text. (b) Estimated errors of the velocity profile at each epoch. 


\section{Glacier PioXI}

(a)

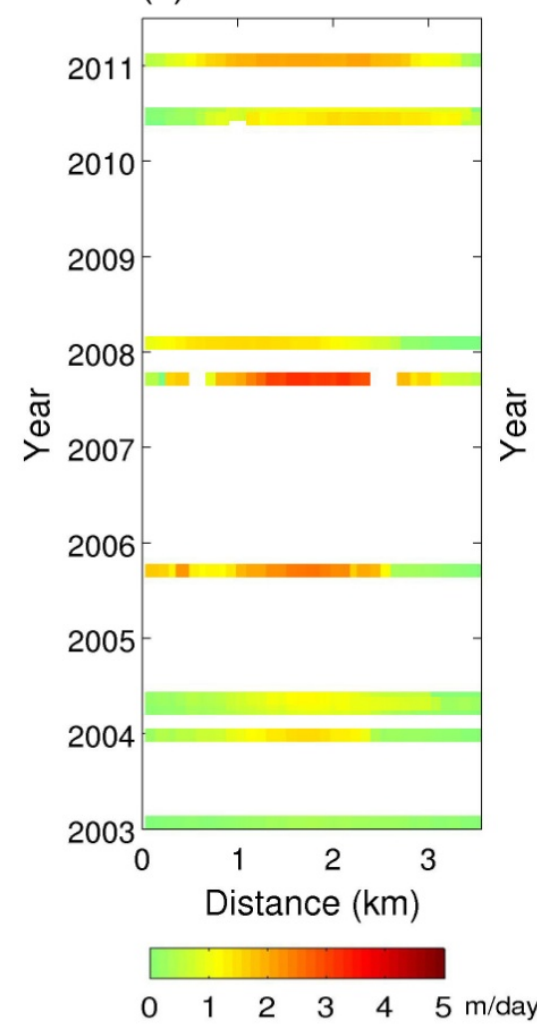

(b)

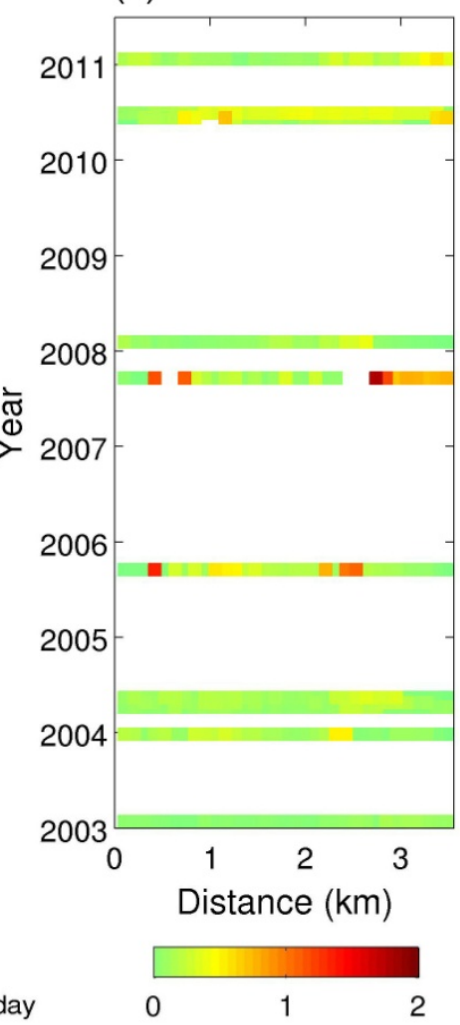

Figure S12: (a) Temporal evolution of the velocity profile A-B in Figure 7 in the main text. (b) Estimated errors of the velocity profile at each epoch. 
(a)

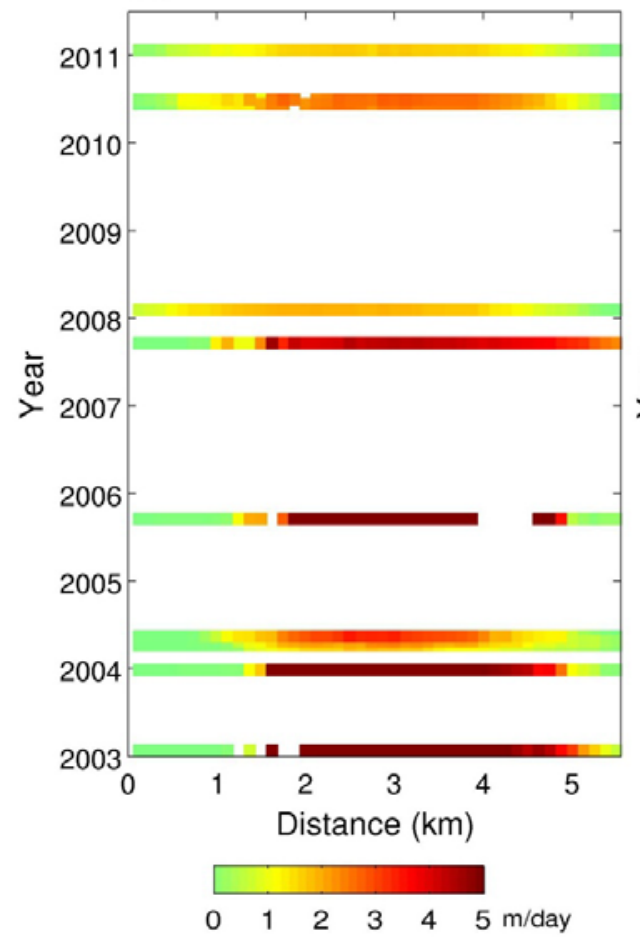

(c)

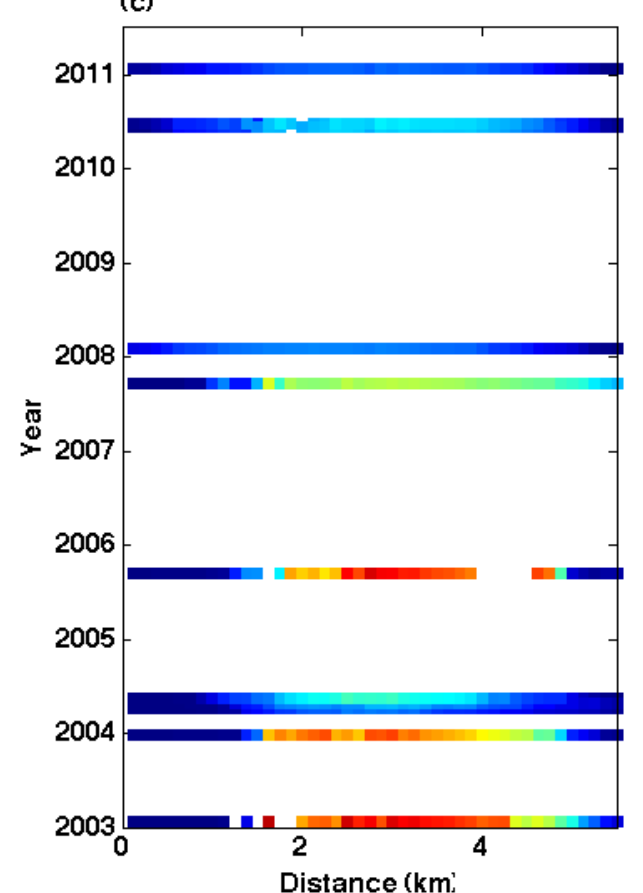

(b)

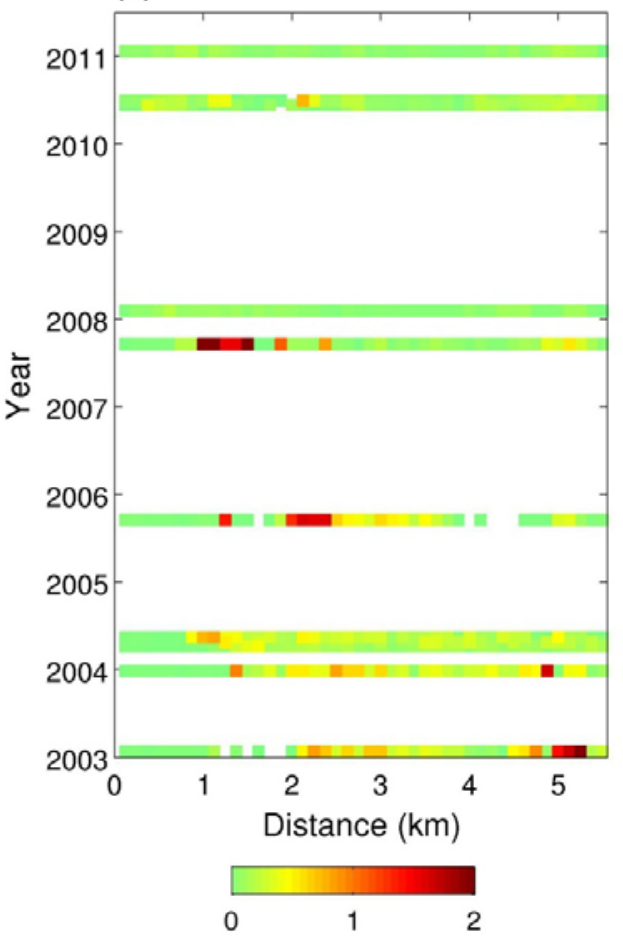

Figure S13: (a) Temporal evolution of the velocity profile C-D in Figure 7 in the main text. The velocities greater than 5 $\mathrm{m}$ /day are saturated in the color scale; see also (c). (b) Estimated errors of the velocity profile at each epoch. (c) Same temporal evolution in (a), but with different color scale and velocity range.

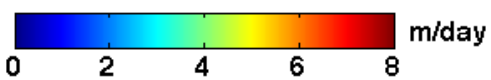


(a)

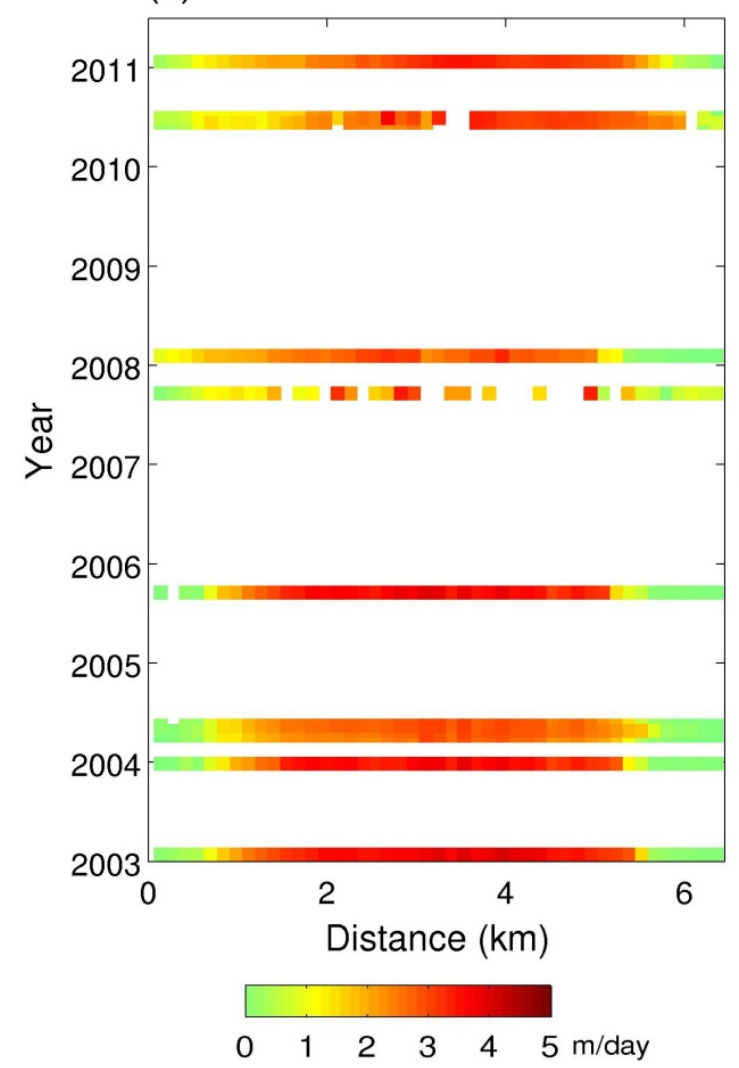

(b)

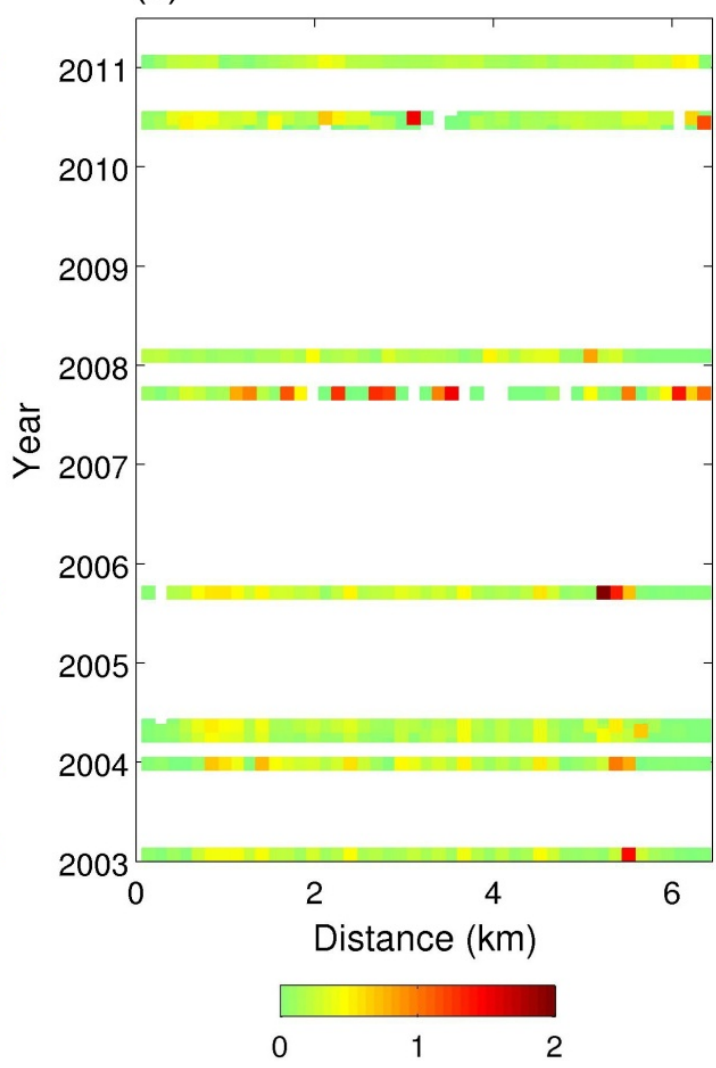

Figure S14: (a) Temporal evolution of the velocity profile E-F in Figure 7 in the main text. (b) Estimated errors of the velocity profile at each epoch. 


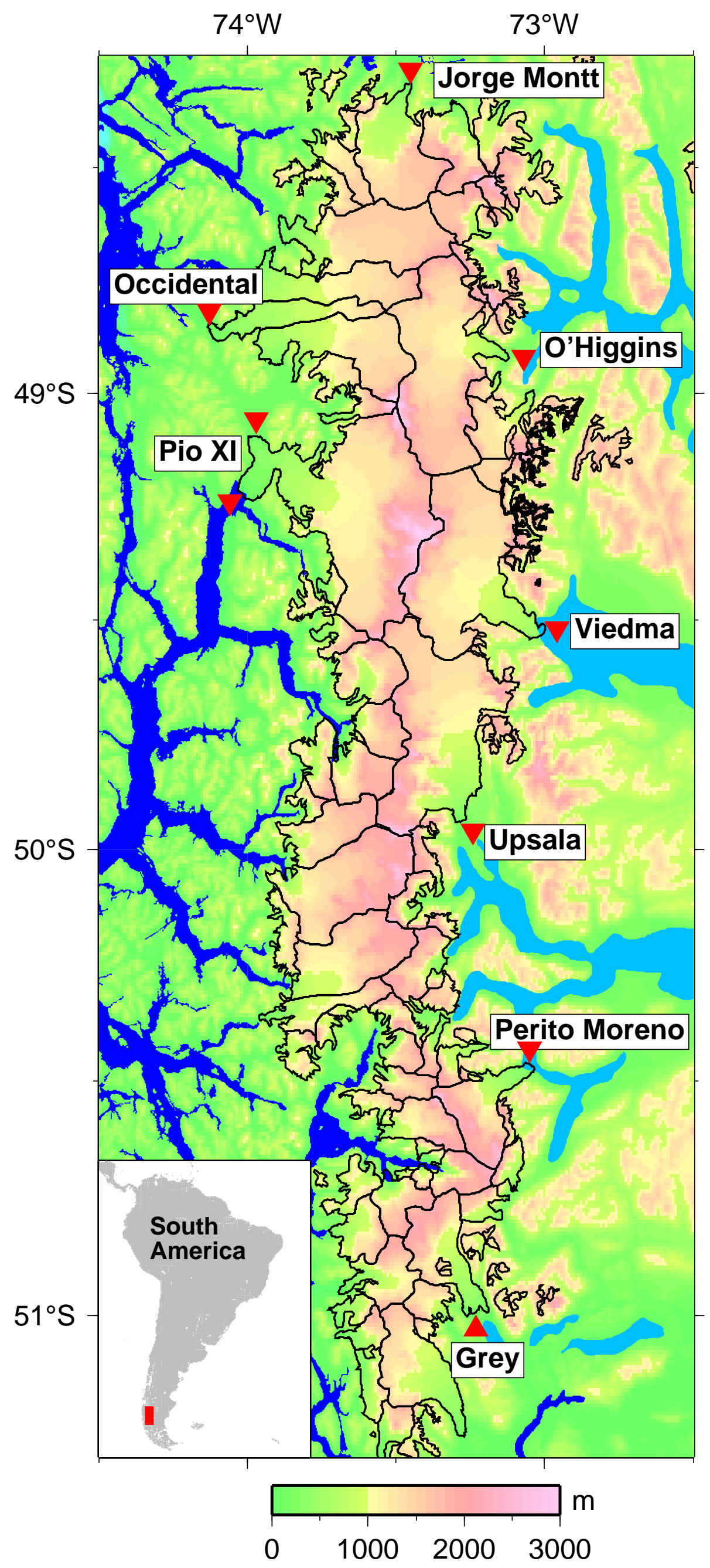




\section{(a)}

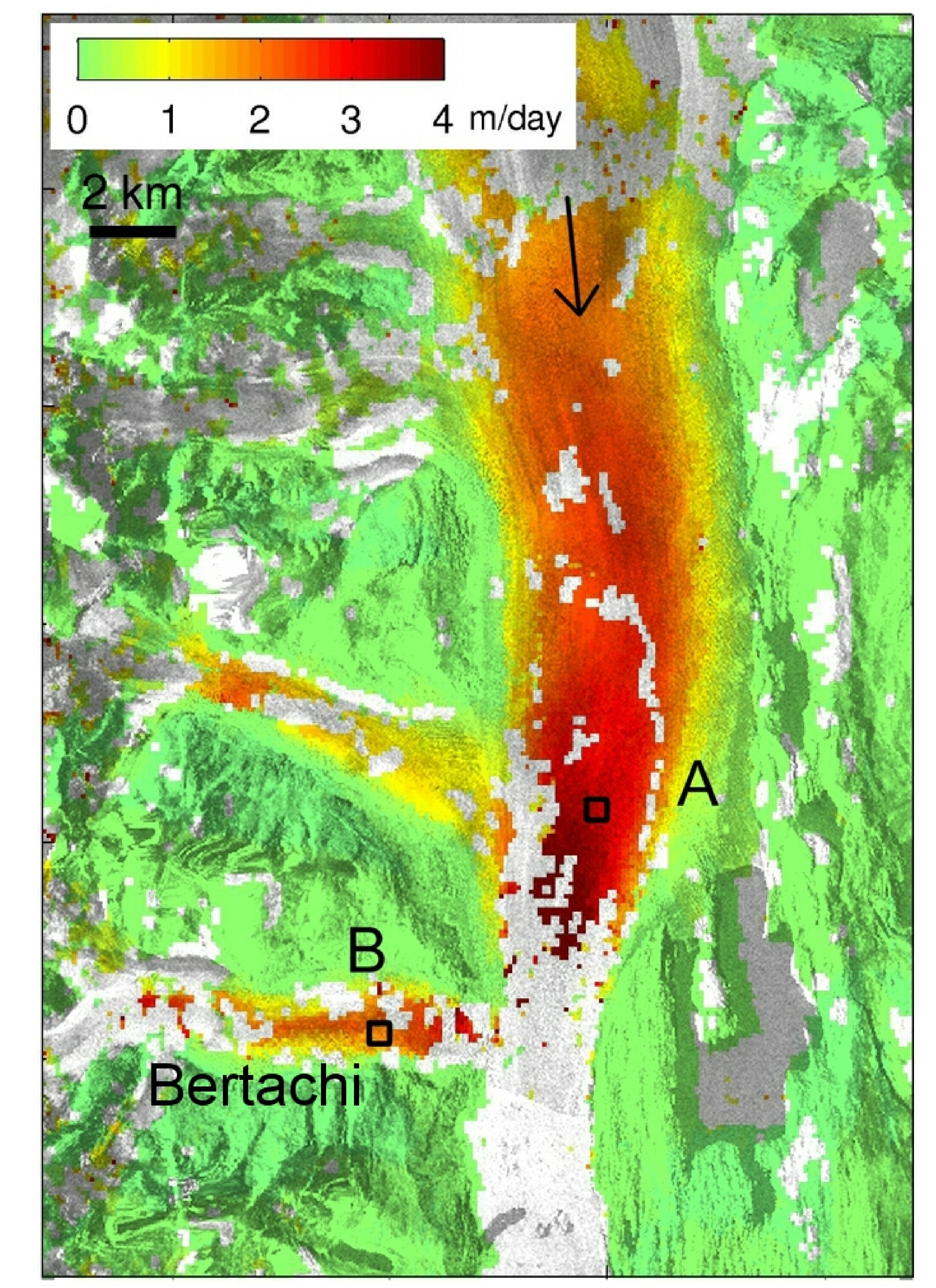

(b)

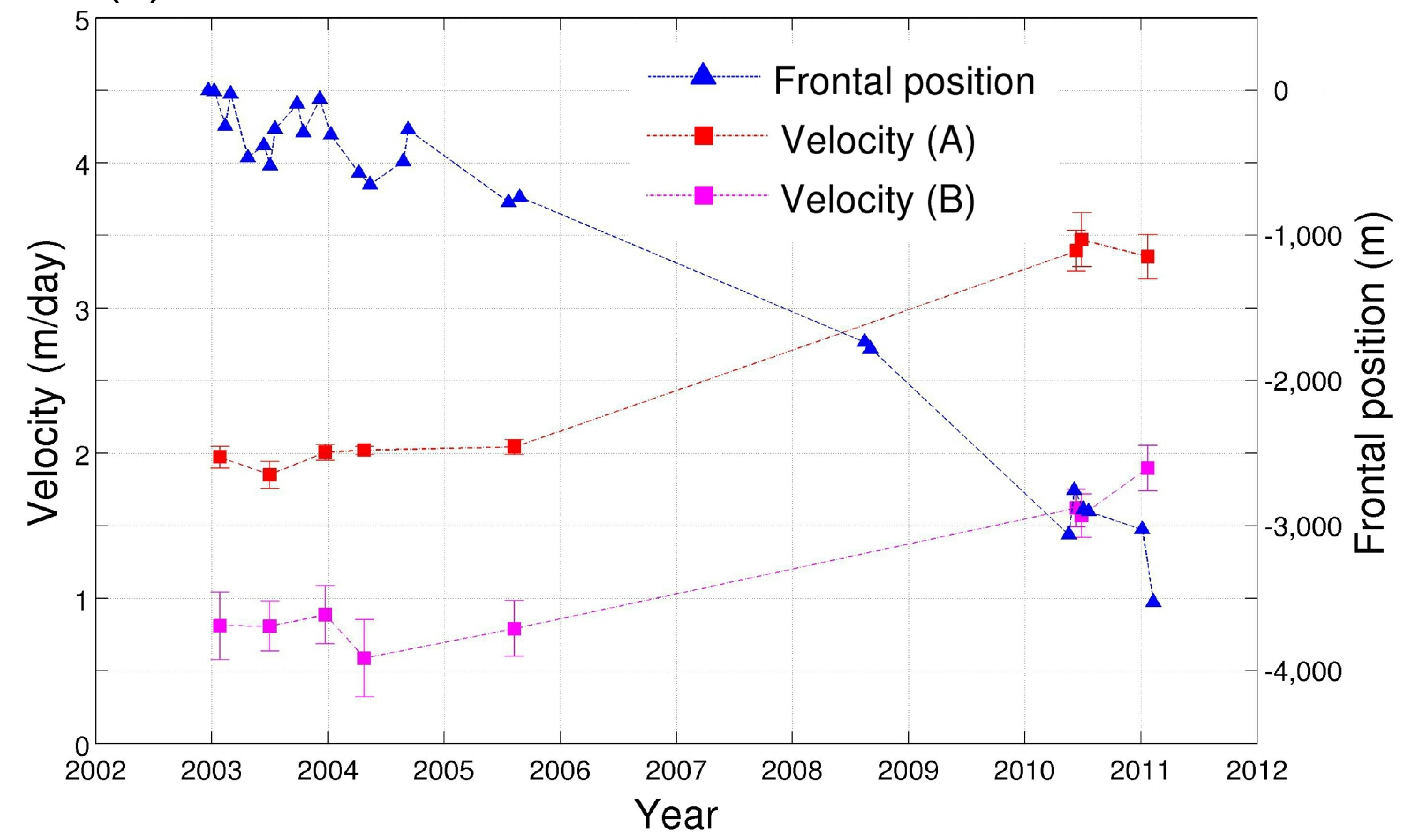


$2002 / 12 / 20$ $2003 / 01 / 08$ $2003 / 02 / 12$ $2003 / 02 / 28$ $2003 / 04 / 23$ $2003 / 06 / 13$ $2003 / 07 / 02$ $2003 / 07 / 18$ $2003 / 09 / 26$ $2003 / 10 / 15$ $2003 / 12 / 05$ $2004 / 01 / 09$ 2004/04/07
$2004 / 05 / 12$ $2004 / 08 / 25$ $2004 / 09 / 10$ 2005/07/22 $2005 / 08 / 26$ 2008/08/15 2008/09/03 2010/05/19 2010/06/05 2010/07/04 2010/07/21 2011/01/04 $2011 / 02 / 19$ 


\section{(a)}

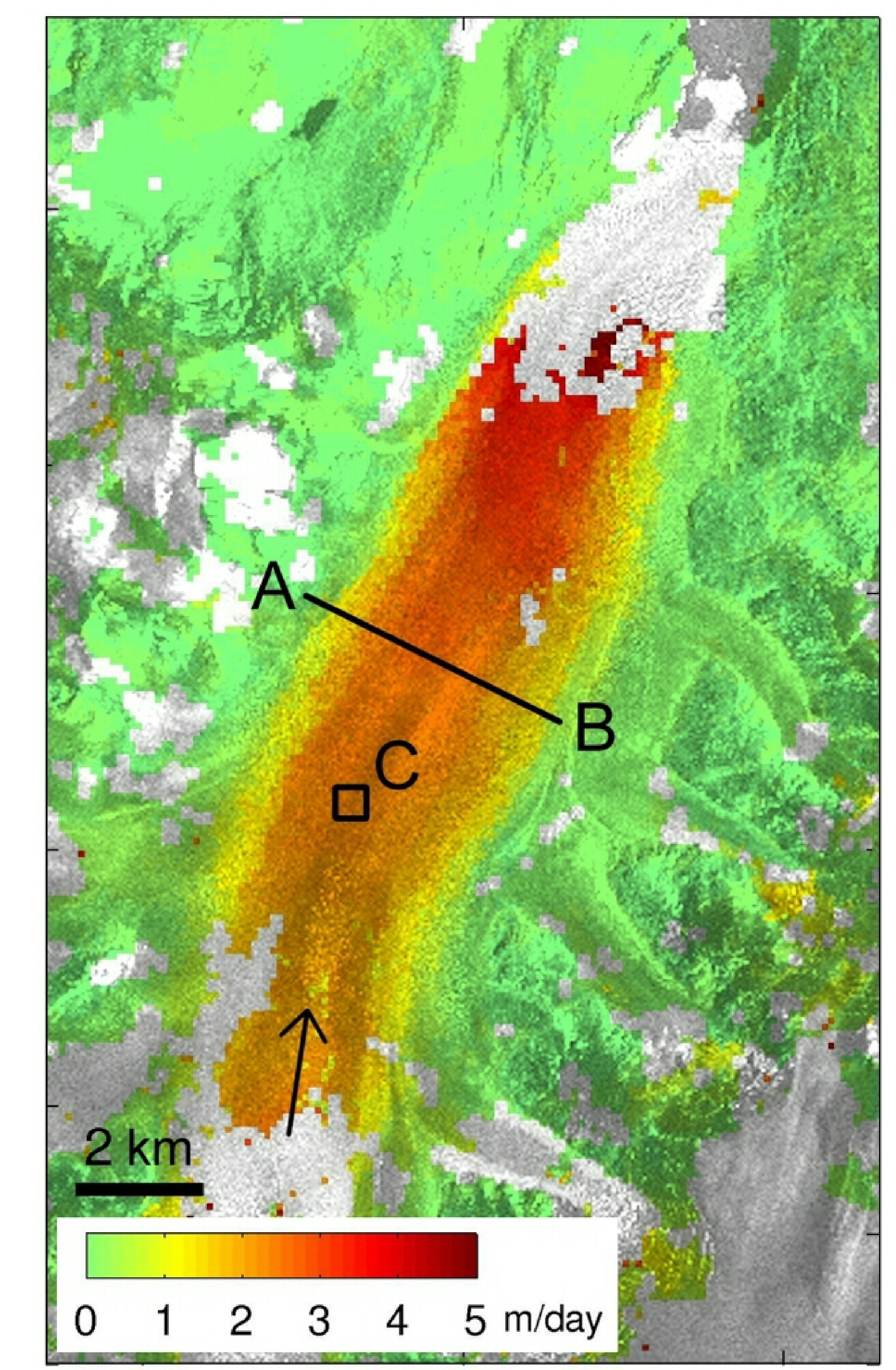

(b)

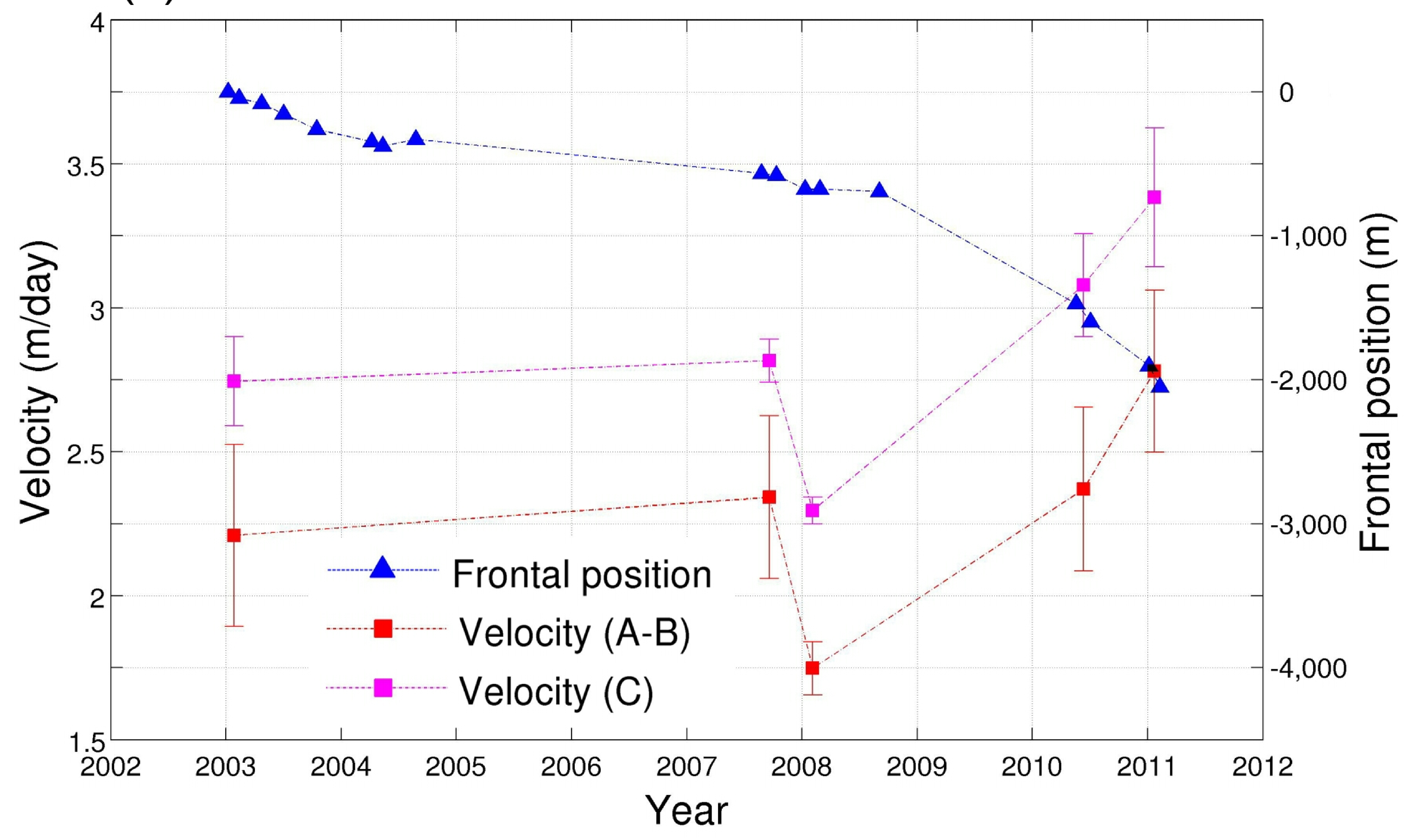




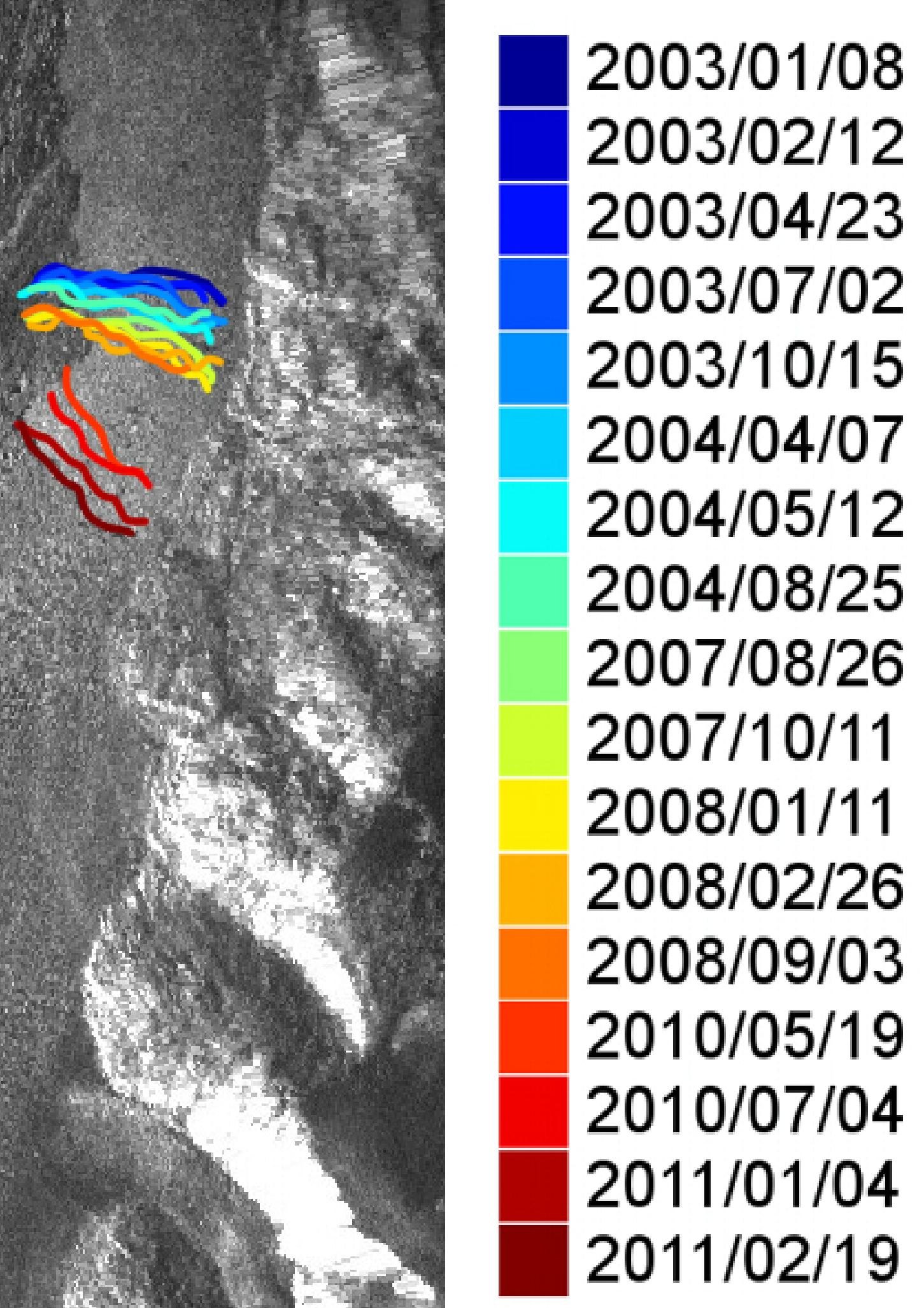


(a)

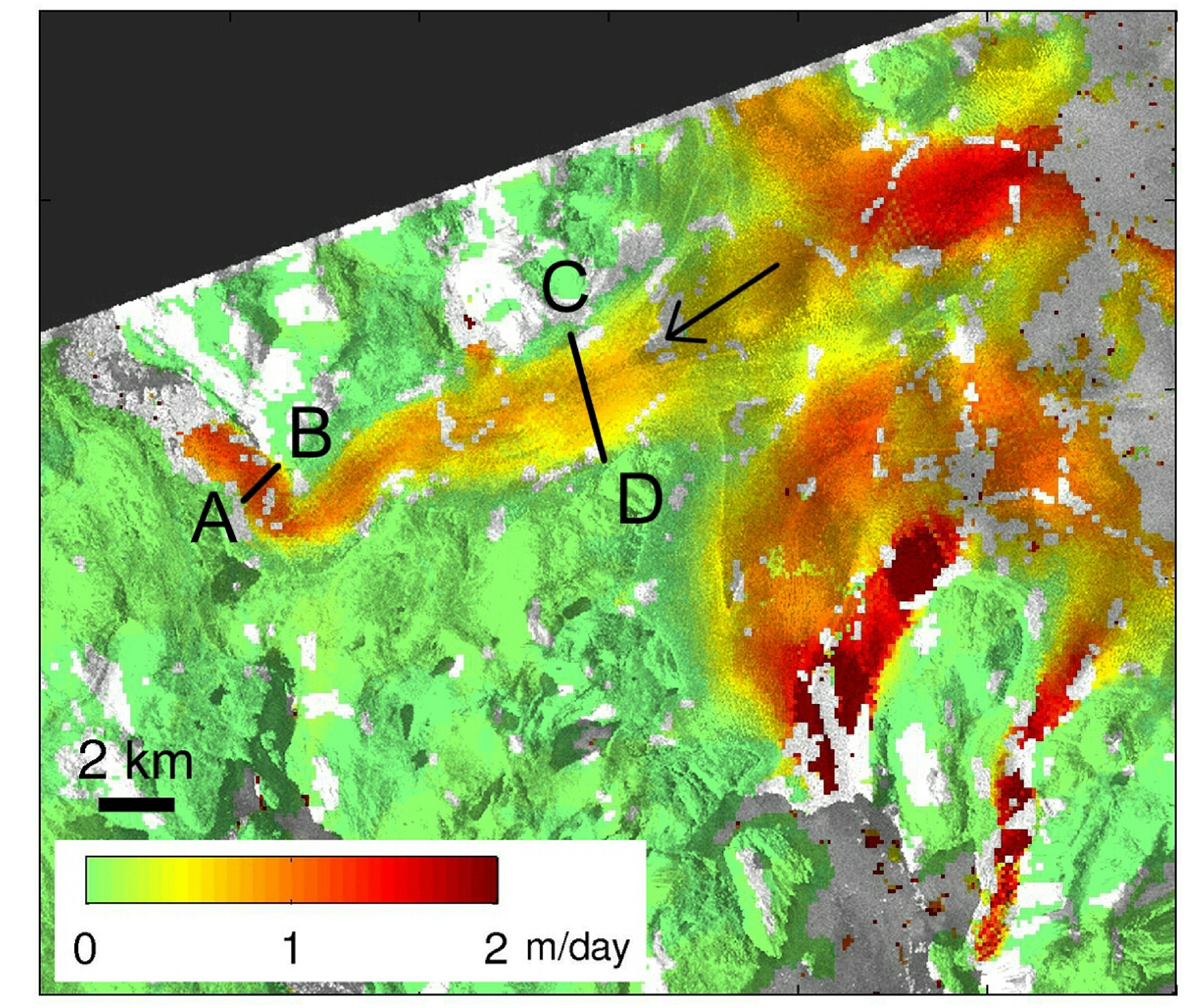

(b)

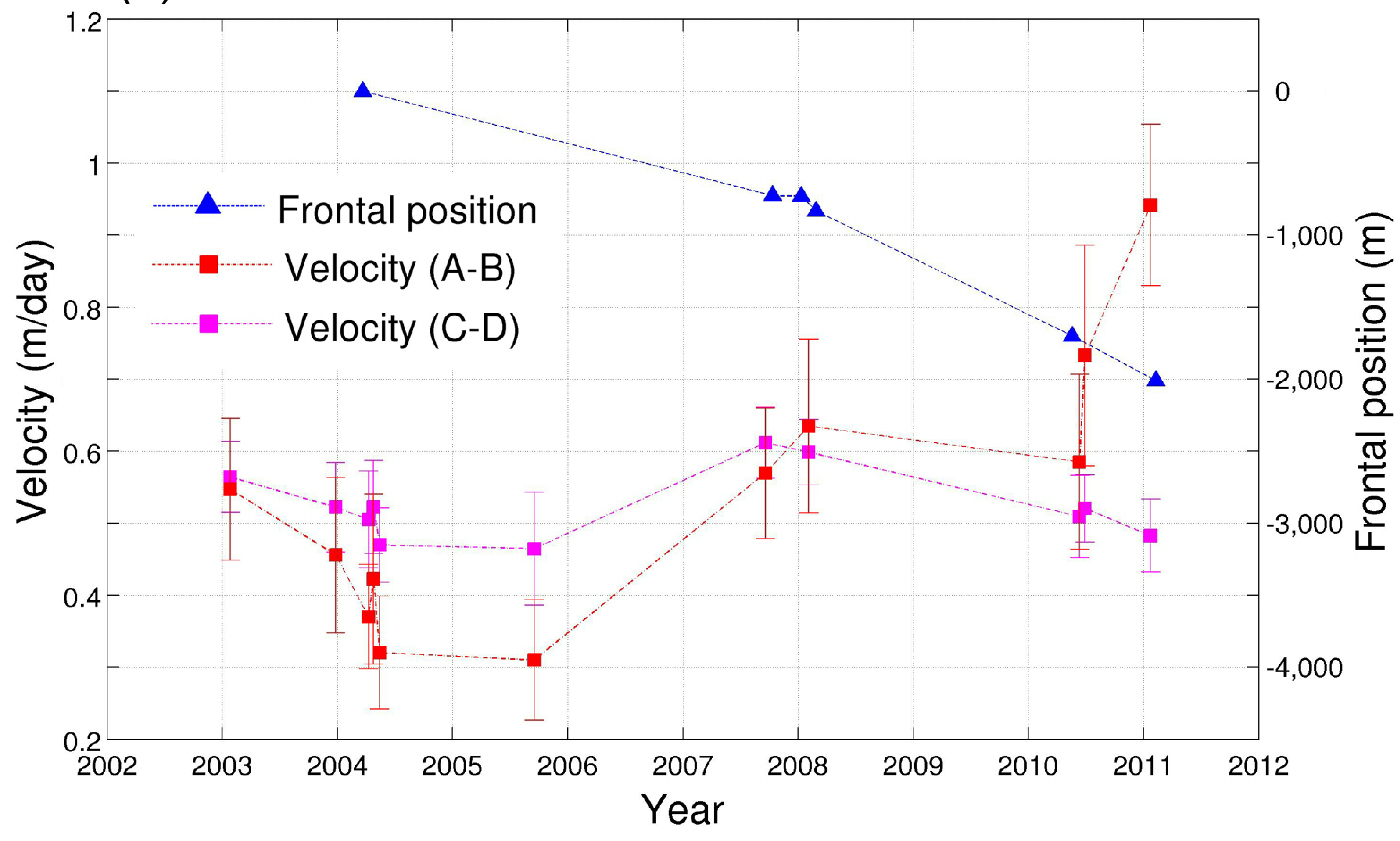


(a)

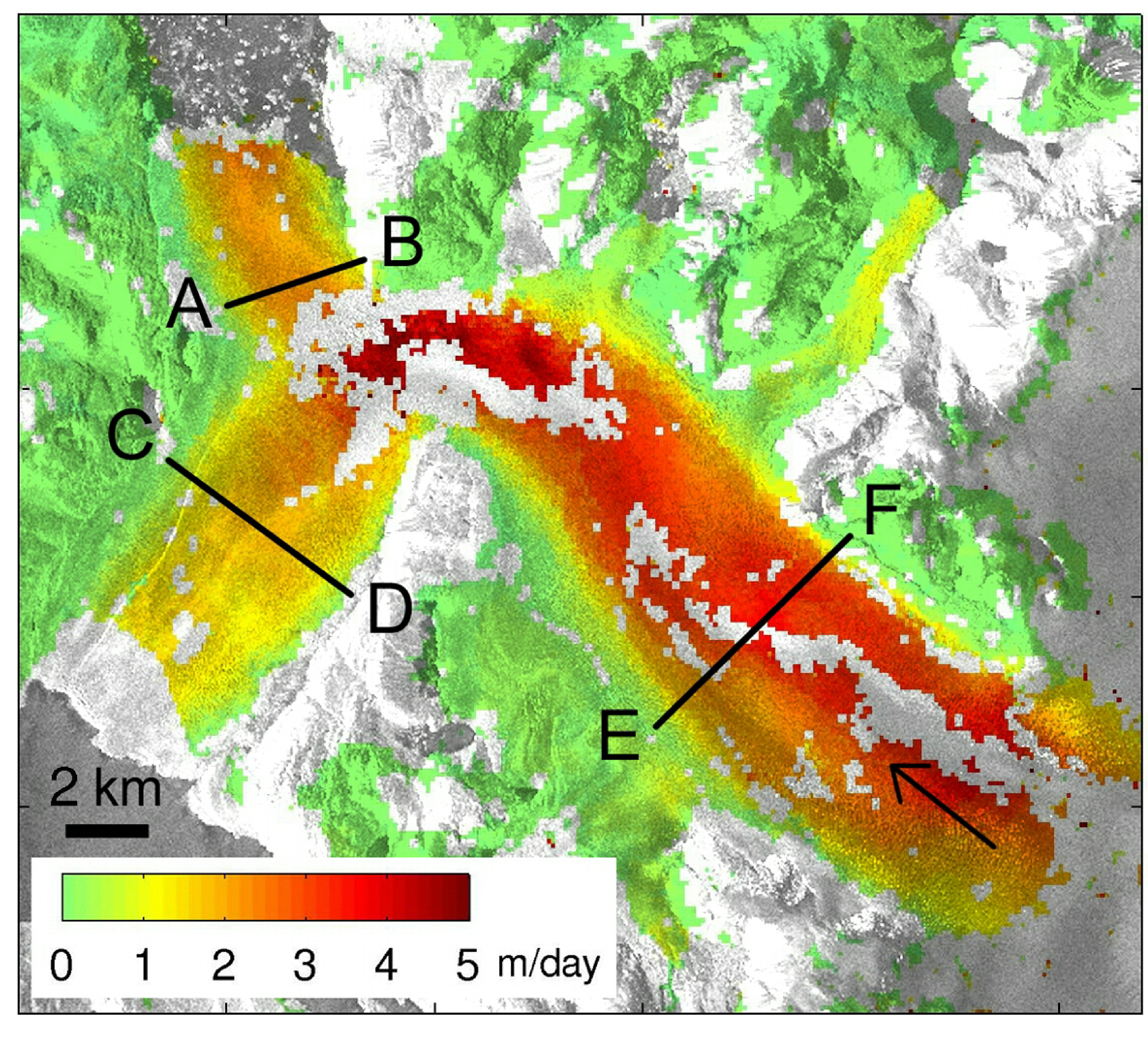

(d)

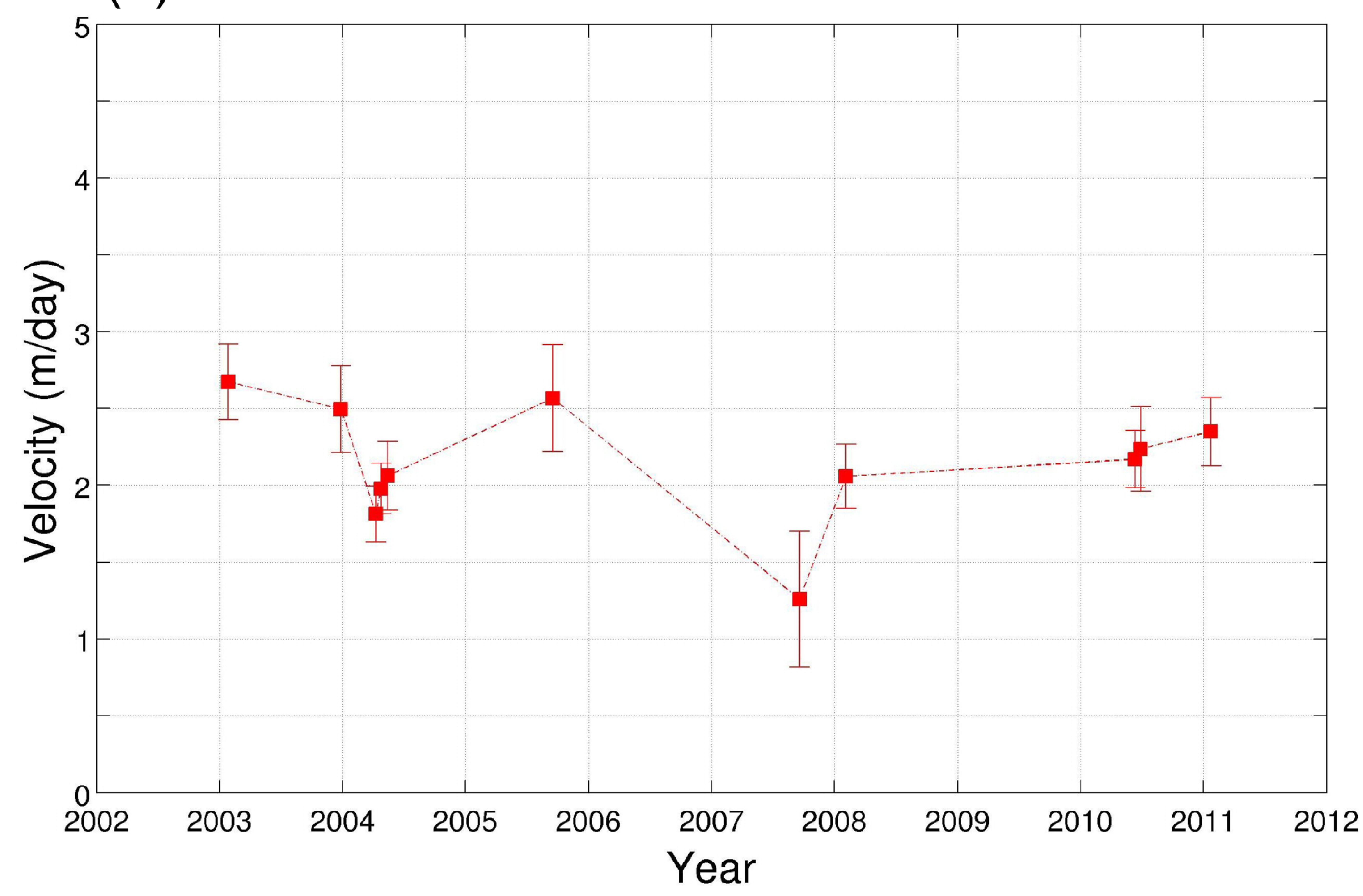

(b)

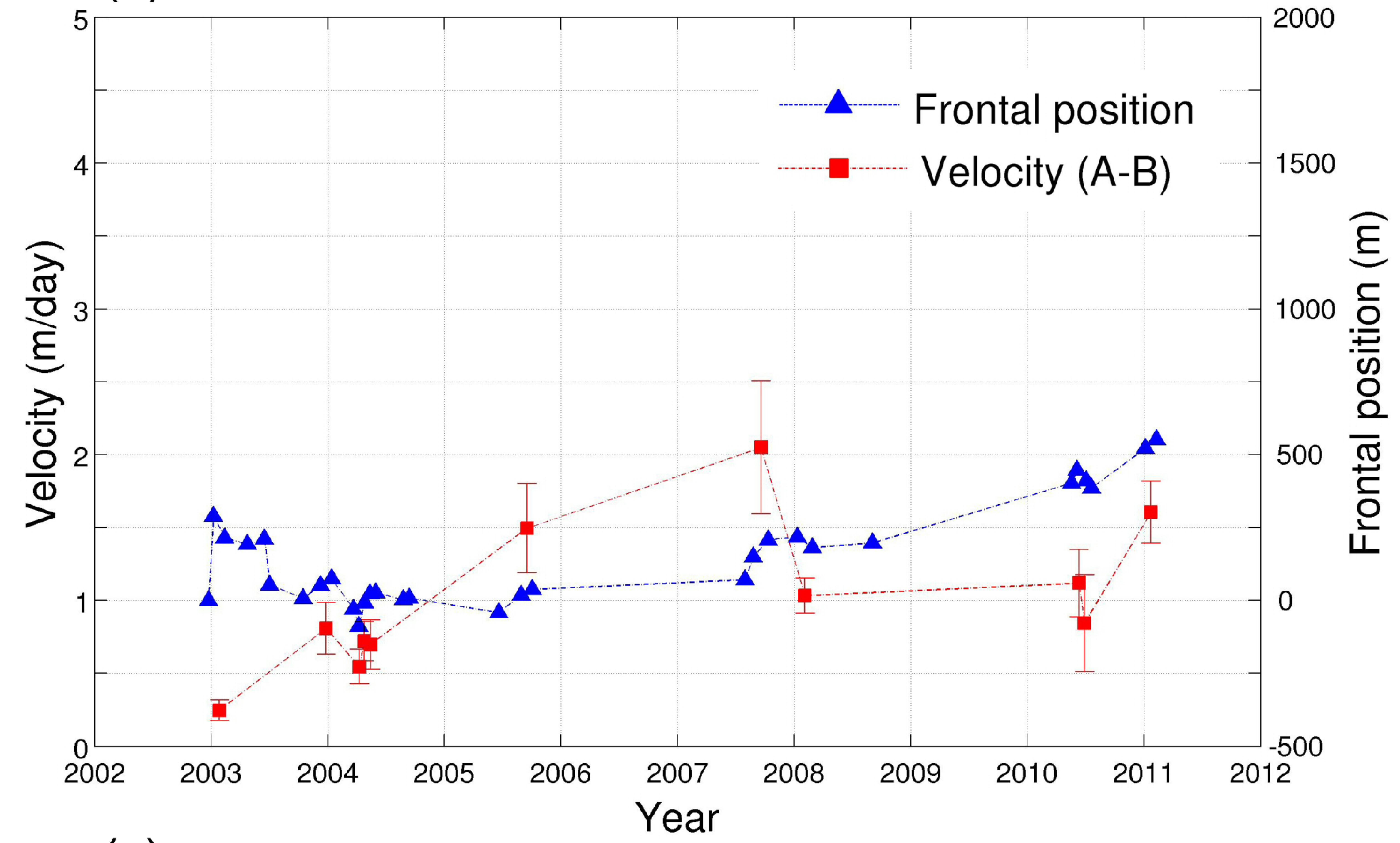

(c)

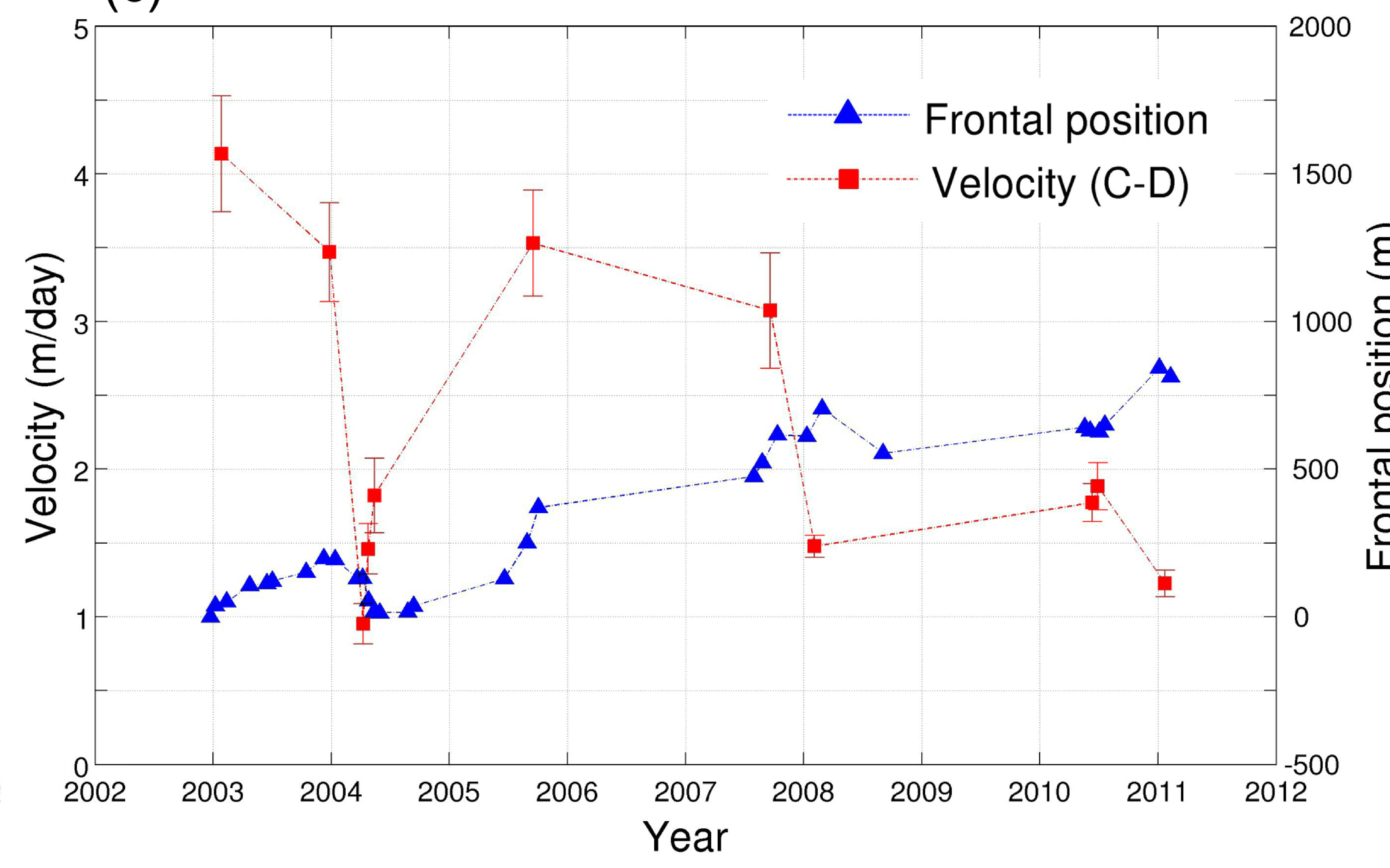




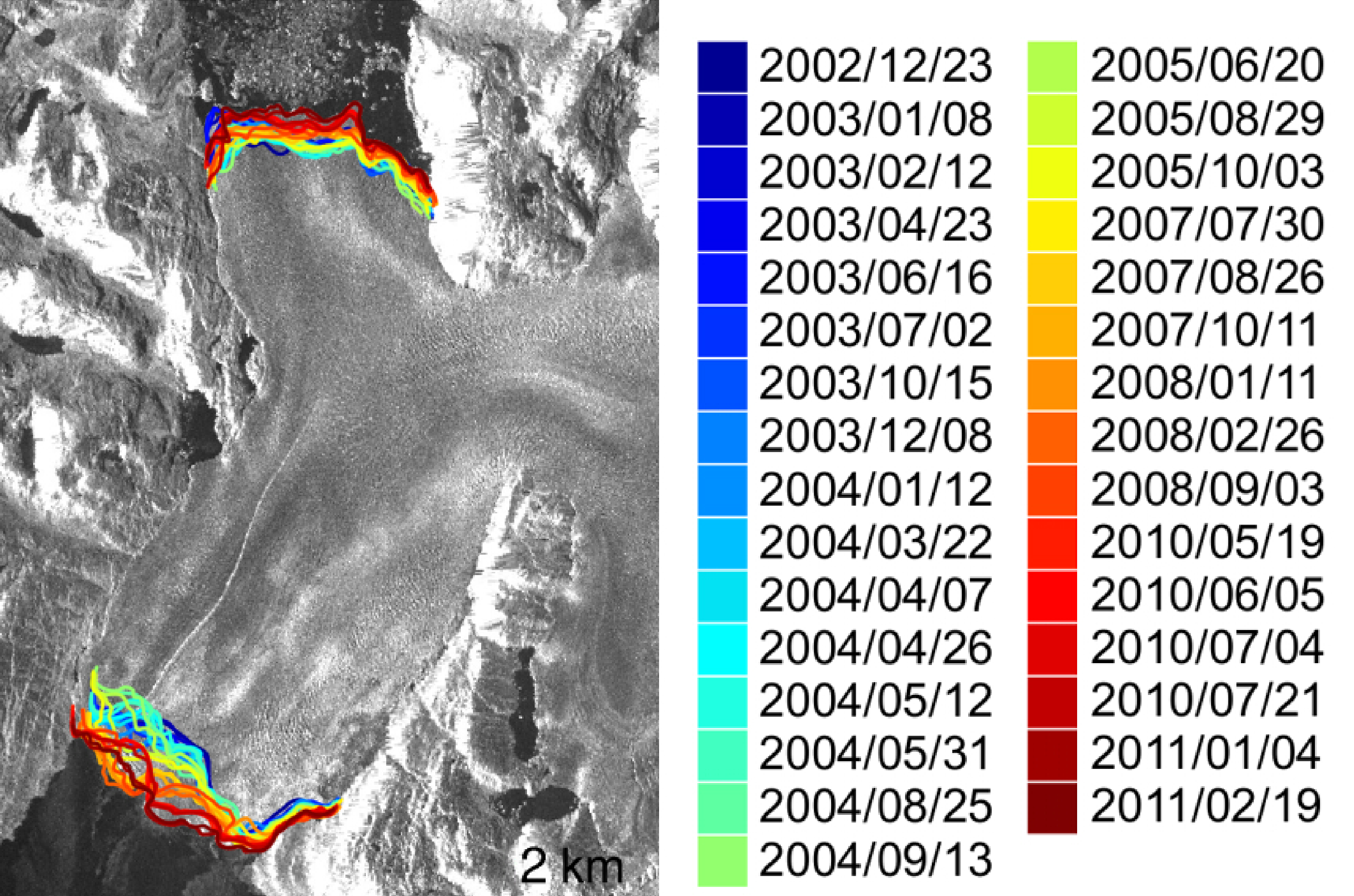


(a)

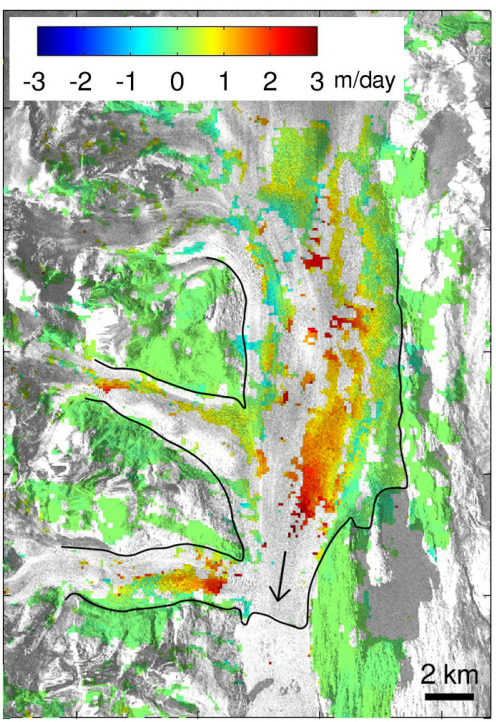

(b)

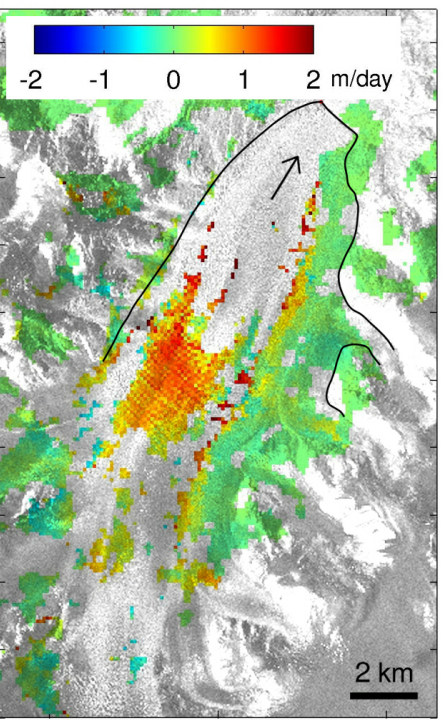

(c)

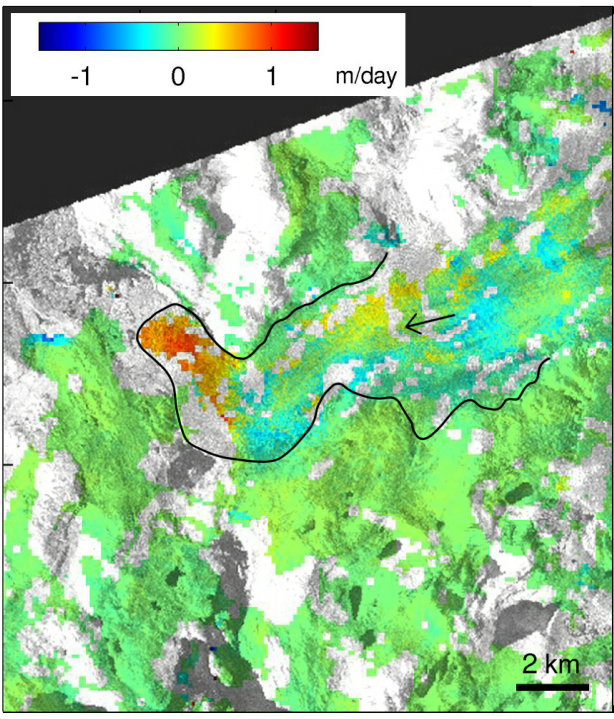

